أثر استخدام أساليب مختلفة لوضع الأهداف في تعلم مهارة التصويب من القفز في كرة السلة

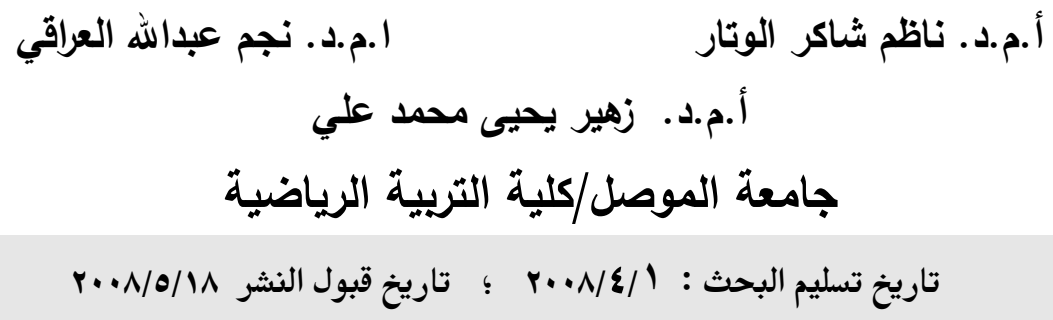

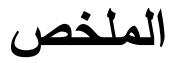

تعد الأهداف من المقومات النفسية التي ترتكز عليها أساليب زيادة الدافعية في مجال

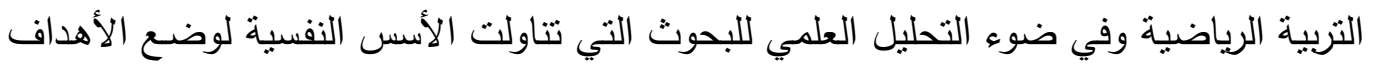

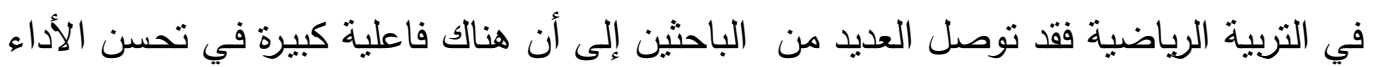

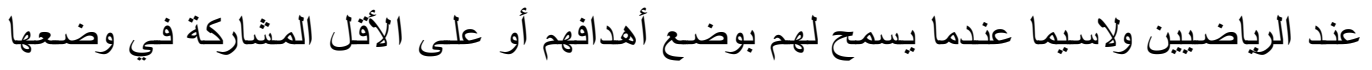

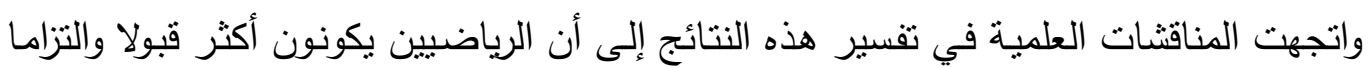
بالأهداف التي يضعونها بأنفسه إذ يعد الهدف بمثابة إحدى آليات الدافعية التي تستخدم لتحديد الاتجاه نحو الهدف. - الافل

مشكلة البحث تحددت في محاولة معرفة ماهية النأثير النفسي لأسلوب وضع الأهداف في تطوير مهارة التصويبة السلمية وهدف البحث إلى التعرف على اثثر استخدام أساليب مختلفة

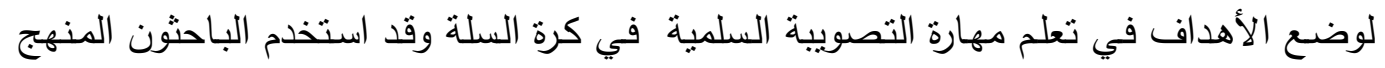
التجريبي سبيلا لحل مشكلة البحث إذ تم اختيار تصميم المجموعات التجريبية المتكافئة ذات التهات

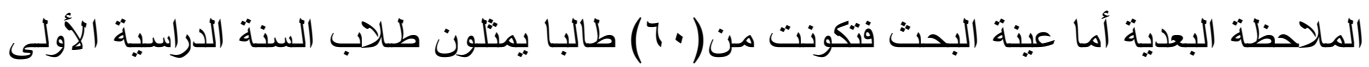

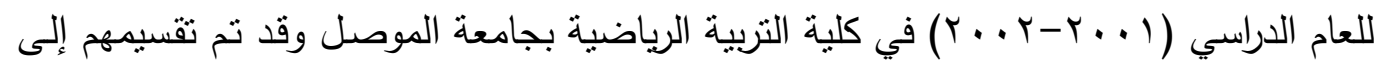

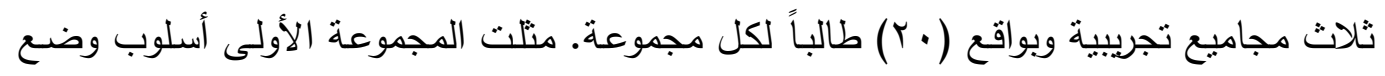

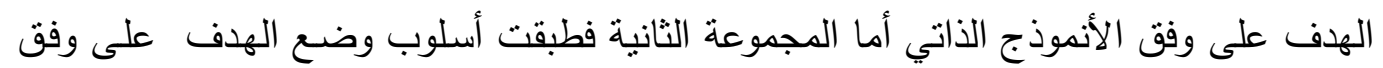

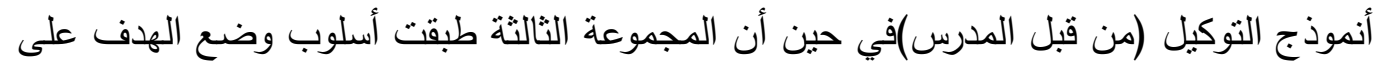

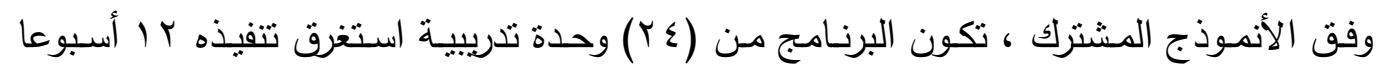

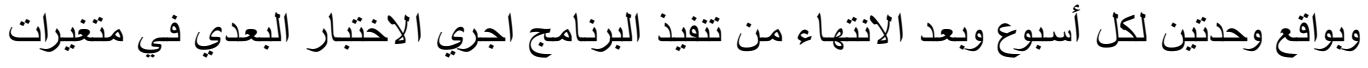




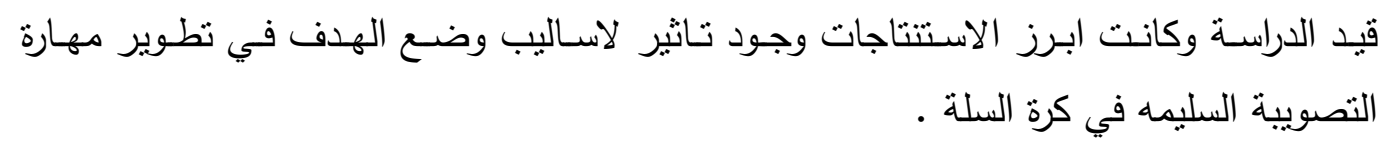

(Abstract)

\title{
The Effects of Using Different Styles of Goals Setting in Learning jump shooting skill basketball
}

\author{
Dr.Nadhim Al-Wattar Dr.Najim.A.Al-I
}

Dr. Zuhir yahya .M.Ali

University of Mosul/College of Physical Education

Goals are psychological components on which the important successions can be depending in the field of sport education. In the lights of scientific analyses of researches, it is found that goals have a great effectiveness to improve the athlete's performance particularly when it is allowed to those athletes themselves to set their own goals or at least participate in this process. The scientific discussion trend to interpretate these results according to that athletes be more acceptable and commitment to goals which set by themselves because of goal is an important mechanism of motivation used to determined the direction of goal. The problem of the research is confined to be acquainted with the essence of psychological effect of goals setting style on The jump shooting skill. Choosing a proper style of goal setting is an important difficulty facing the teachers, coaches, and athletes when applying educational and training curricula to achieve their goals .The research aims at revealing :The psychological effect of goals setting on Learning The jump shooting skill.

The researchers had hypothesized There are significance differences statistically in the style of goals setting among the three experimental groups at post-test for improving skills of jump shooting:

The researchers had used the experimental method, since it is convenient to the nature of research .The equal multi grouped experimental design with post-tests was taken up. The researchers had achieved the equality among the three experimental groups in variables of the chronological age, the high, and the weight; in addition to certain physical qualities .The sample was 60 students represents the first-class students of sport education collage, Mosul University, the academic year of 2001-2002. The sample divided into three experimental groups with twenty students each. 
The first experimental group represents the style of goal setting according to the self-pattern. The second experimental group represents the style of goal setting according to the delegation pattern (by teacher). The third experimental group represents the style of goal setting according to the combined pattern.

The program included 24 sessions and lasted 12 weeks with 2 sessions in a week. Having achieved these programs, the post-test had done for the variables in question. The researchers had concluded There are significance differences statistically among the three experimental groups at post-test for improving skills of jump shooting.

The researchers had recommended the following :Applying the styles of goal setting when preparing the basketball curricula in college and departments of sport education in Iraq.

$$
\begin{aligned}
& \text { 1- 1 - 1 التعريف بالبحث } \\
& 1 \text { - } 1 \text { المقدمة و أهمية البحث } \\
& \text { تعد الاهداف من المقومات النفسية التي تقوم عليها سياقات مهمـة في مجال التربيـة } \\
& \text { الرياضية اذ لم تستثنَ البحوث العلمية في هذا الاتجاه تاثيراتها المهمـة في زيادة الدافعية نحو } \\
& \text { الاداء والانجاز الرياضي. } \\
& \text { وقد اثشار العديد من الباحثين أمثال (كيلو ولاندوز) (Kellow \& Landoz, 1995) في هذا }
\end{aligned}
$$

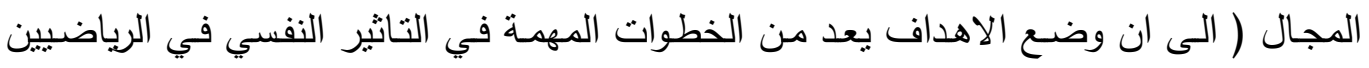

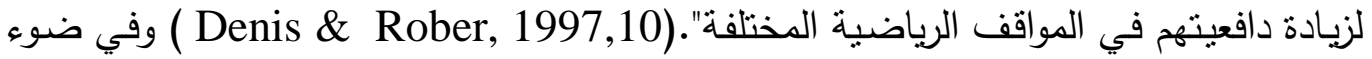

$$
\begin{aligned}
& \text { التحليلات العليـة للبحوث ذات العلاقة بهذا الموضوع وجد ان هناك فاعلية كبيرة في تطور } \\
& \text { الاداء عند الرياضيين ولاسيماعندما يسمح لهم بوضع اهدافهم او على الاقل عند مشاركتهم في }
\end{aligned}
$$

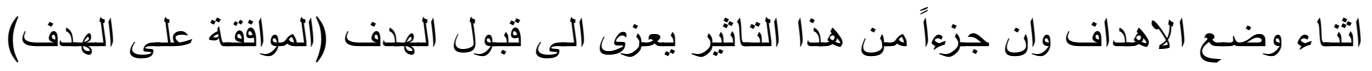

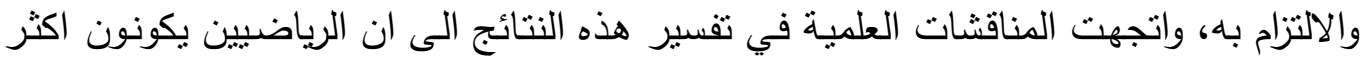

$$
\begin{aligned}
& \text { قبولا والتزاما بالاهداف التي يضعونها بانفسهم مقارنة بتلك الاهداف التي وضعت لهم من قبل } \\
& \text { الآخرين. اذ يعد الهدف بمثابة احدى آليات الدافعية المهمة التي تستخدم في تحديد الاتجاه نحو } \\
& \text { الهذف والتي تؤثز بدورها في اكمال السلسلة المنطقية في تحقيق الهدف الذي يصفه المدرب } \\
& \text { والمنترب على حذ سواء ويمكن عدّ هذه الآلية احدى العوامل المهمة الني تعمل على زيادة تركيز }
\end{aligned}
$$

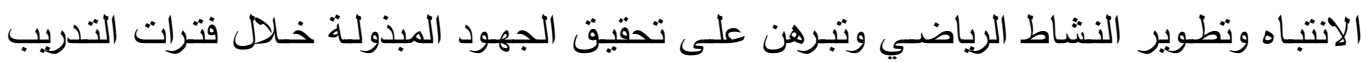




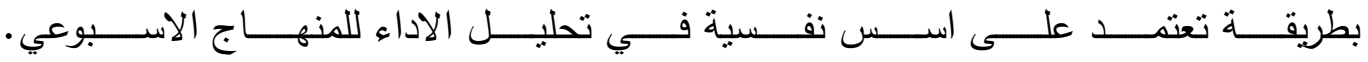
(Suinn, 1994,179)

ولما كانت لعبة كرة السلة احدى الفعاليات الرياضية الني تحتل موقعا مهما بين الالعاب الرياضية الاخرى فان مستوى تطوير الاداء لمهارتها واساليب تدريسها وفن ممارسة اللعبة يحتاج

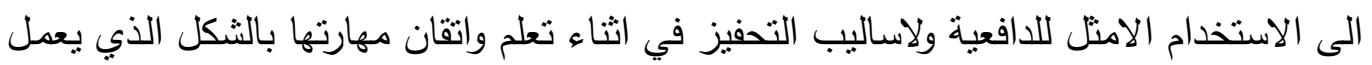

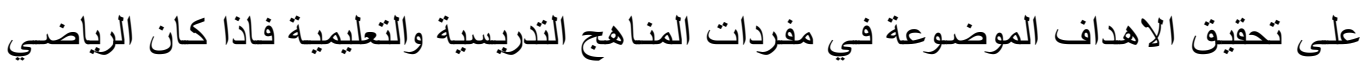

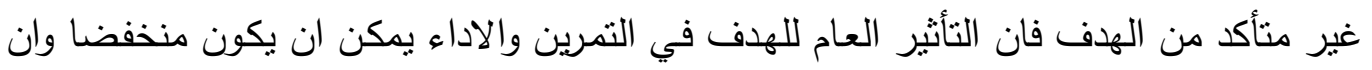
وضوح الهدف يعني ببساطة الى أي حد يفهم الرياضيون الاهداف ويشعرون بانها واضحة وان

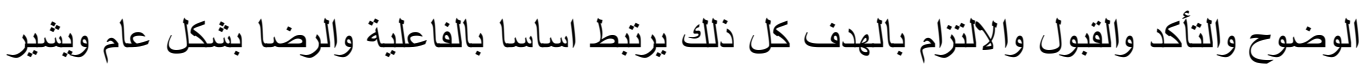
الى مستوى التباين في الاداء المرغوب فيه فعلا. وقد وجد كل من (وايت ولدك ) (Wihte \& Ledk, 1984) ) نسبة تحقيق الاهداف بصورة عامة تحتل الاولوية في مشاركة الرياضيين في عمليات وضع الاهداف واجراءاتها وفي

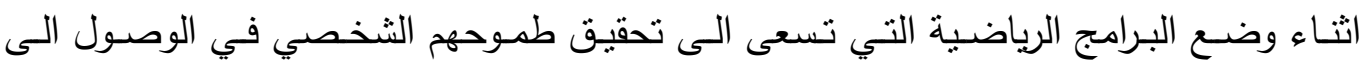

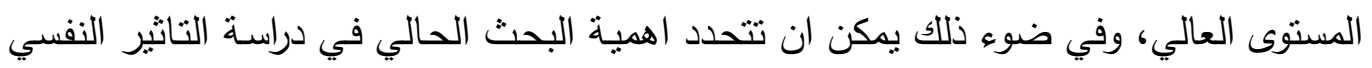

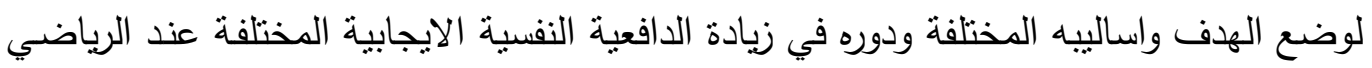
لتطوير مستوى الاداء وتحسينه لتحقيق النتائج المرجوة في عمليتي التعلم والتدريب في التربية

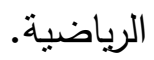

فضلاً عن دراسة العلاقة الني يحدثها التأثثر النفسي في تحديد الاهداف في اطار تباين المواقف والظروف الرياضية التي يتعرض لها الرياضي والبحث عن السبل الكفيلة بتحسين الاداء

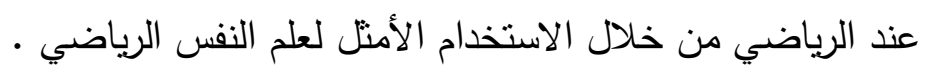

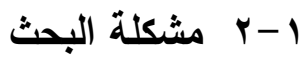

ان اسـاليب وضـع الاهداف في ابسط صسورها وغاياتها يمكن ان تقدم وتوضـح الطريق

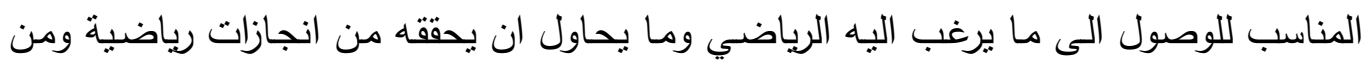

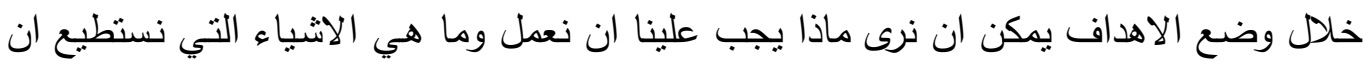

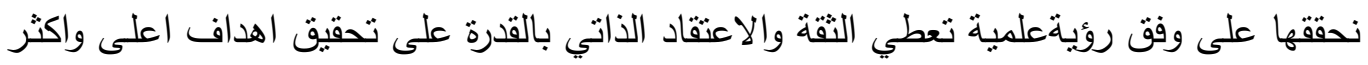
صعوبة، والمشكلة الاساسية التي يجب التصدي لها هي ليست وضع الهدف وحده فحسب وما

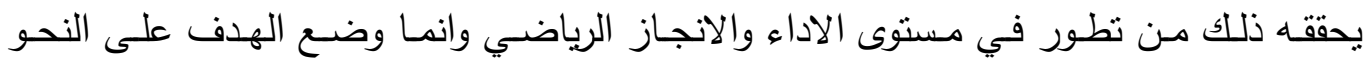

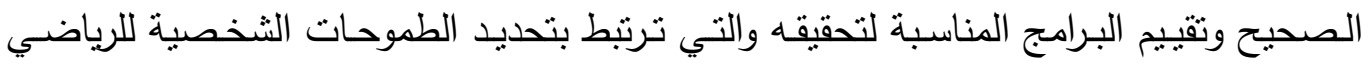

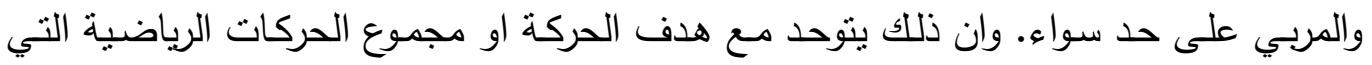


تتحدد على وفق مفاهيم اكثر شمولية باختلاف وسائل القياس التي يمكن ان تقيس تحقيق الهدف باساليب التحديد الذاتي، المشترك، والتوكيل. ومـع اختلاف الآراء في استخدام الاسلوب الامثل لوضـع الاهداف فقد اشـار كل من (رايبرج

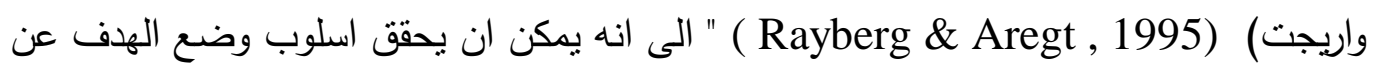

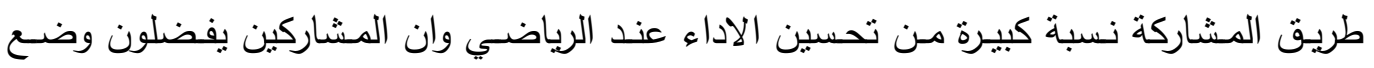

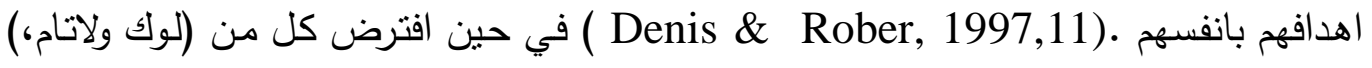
(Look \& Latham , 1990) " ان المشاركة في وضع الاهداف لا نقود الى زيادة الالتزام

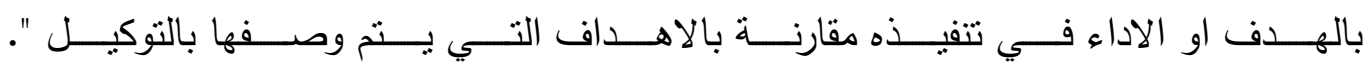
(Suinn,1994,198)

وفي ضوء ما تقدم ومع قلة الدراسات والبحوث الخاصة بتحديد الهدف ذاتيا فان الرياضي

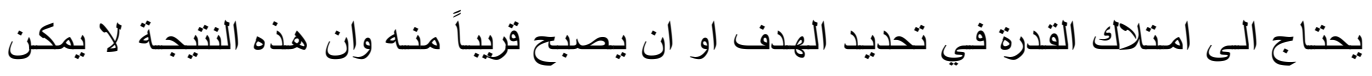

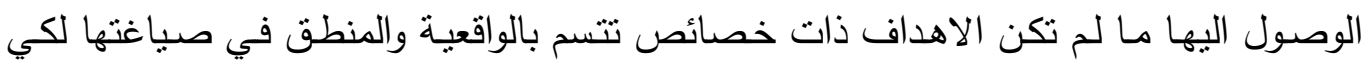

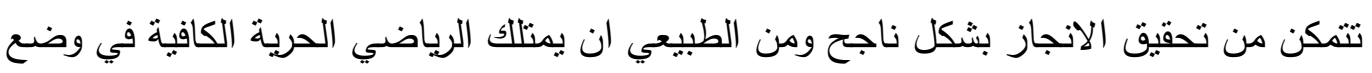
اهدافه واختيار ما هو افضل ولكن هذه العملية يجب ان تتمثل بنظام معين يجعل عملية تحديد

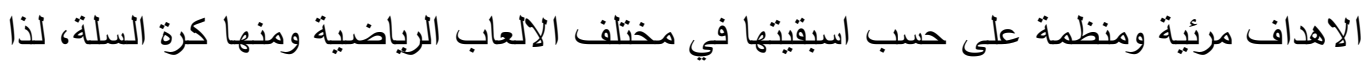

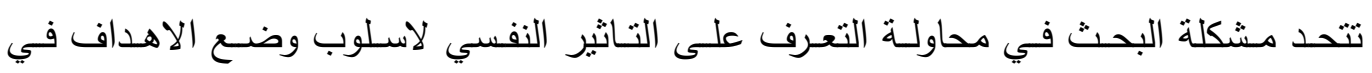
تطويرعدد من انواع التصويب في كرة السلة. إذ إن اختياراسلوب وضع الهدف المناسب يعد من المشكلات المهمة التي نواجه المربين والرياضيين في اقسام وكليات التزبية الرياضية في القطر عند نطبيقهم مناهجهم الدراسية لتحقيق الاهداف التعليمية التي برجونها خلال العام الدراسي بغية تقديم افضل الانجازات العلية لتقدام الحركة الرياضية في القطر ولاسيما في ميدان العمل الأكاديمي.

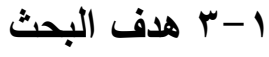

الكثف عن اثر استخدام أساليب مختلفة لوضع الأهداف في تعلم مهارة التصويب من القفز السلمي بكرة السلة.

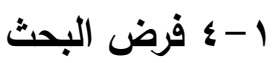

توجد فروق ذات دلالة احصائية بين اساليب وضع الهدف في تعلم مهارة التصويب من الققز بكرة السلة .

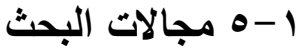

*-المجال البشري : طلاب المرحلة الاولى في كلية التربية الرياضية بجامعة الموصل

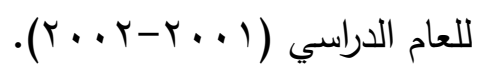


"-المجال المكاني : القاعة الداخلية التابعة لفرع الالعاب الفرقية في كلية التربية الرياضية

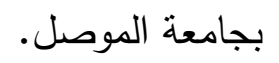

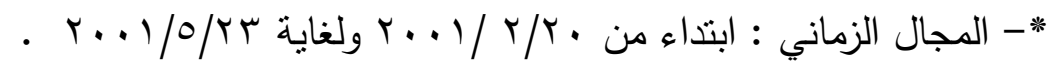

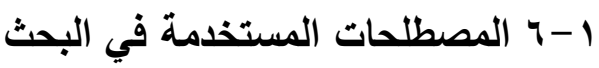

وضع الاهداف

عرفه (علاوي، 991 (191) " الثنيء الذي يريد الفرد تحقيقه ".

وعرفه (هارس) " انه تعيين هوية الثيء الذي يريد الفرد ان يحققه او ينجزه ". وعرفه (كريمروسلكي) " بانه عزم او تصميم او قصد شعوري او واعي او هو ما يحدده الفرد الفيه

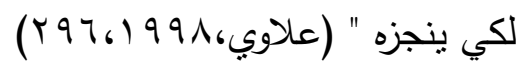

ويعرفه الباحثون اجرائياً " هو التحديد الدقيق للاهداف المراد الوصـول اليها في تعلم مهارة التصويب السلمي من خلال استخدام اساليب مختلفة من وضع الاهداف لنطوير مهارات

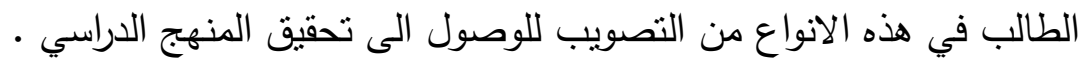

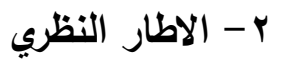

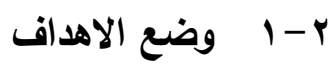

يعد وضع الاهداف من الخطوات العلمية المهمة في مجال التربية الرياضية والتي تتسم بالحداثة

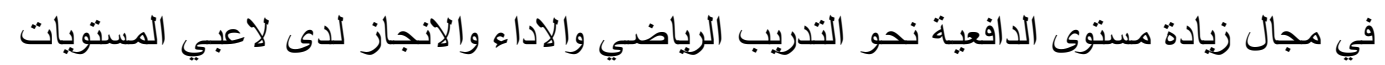
العليا وعلى الرغم من استخدام اسـاليب مختلفة مـن المدربين للارتفاع بمستوى الدافعية لدى

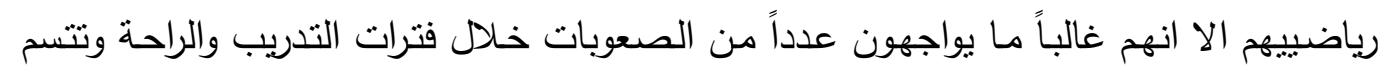
هذه الصعوبات بعدم امكانيـة صياغة الاهداف وتشكيلها بصورة ايجابيـة في مجال التعلم وتطويرالاداء وتحسين الانجاز ويؤدي التأثير لوضع الاهداف دورا كبيرا في تحديد خصوصية التعامل مع المتدرب المتعلم للمهارة. (Curry,1989,112) وان وضـع الاهداف يعطي روئبعيدة المدى و دافعية على المدى القصير ومن خـلال المشاركة في تحديد الاهداف بصورة واضحة فان الرياضي يستطيع القياس والتقاخر في مدى الإى تحقيق تلك الاهداف ".

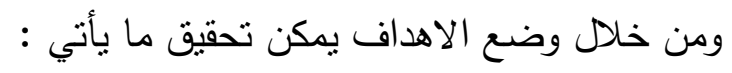

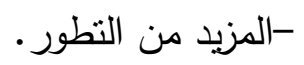
- تحسين الانجاز او تطويره .

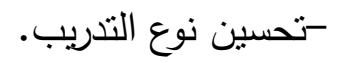
-زيادة الدافعية لتحقيق الهذف. ( Bakket\&etal,1990,p.41) - زيادة (التفاخر والرضا في الانجاز ). 


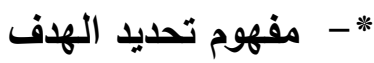

يعد تحديد الهدف في التربية الرياضية مهما وضروريا للانجاز وممثنلا للسلوك وان عملية تحديد الاهداف تساعد في تحديد الدوافع الضرورية لظهور السلوك المطلوب لتحقيق الهدف، واتجهت الدراسـات الاوليـة في هذا المجال الى وصف الهدف إحدى آليات الدافعيـة المهمهة، ويمكن عد هذه الآلية احد العوامل المهمة التي تعدل على زيادة تركيز الانتباه وتطوبر النشاط الرياضي وتبرهن على تحقيق الجهود المبذولة خلال فترات التدريب بطريقة علمية تعتمد على الأسس النفسيتفي تحليل مضدون الاداء. ويمكن القول ان تحديد الهدف هو القاعدة المناسبة التي تنبى على اساسها الدافعية نحو الانجاز من خلال برامج زمنية محددة على مدار البرنامج التدريبي الذي يضعه المدرب خلال الموسم الرياضي.(Rushall,1996,218)

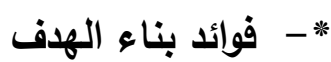
ان تحديـد الاهـداف خـلال الممارسـة الرباضـية يسـح بتحقيـق فوائـد عديـدة يـأني في

$$
\text { - }
$$

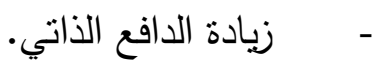$$
\text { - - تمية الشعور بالفخر والرضا والثقة بالنفس. }
$$$$
\text { كما يمكن تحديد فوائد بناء الاهداف بما يأتي: }
$$$$
\text { أ. التاثير المباشر لوضع الاهداف في السلوك ويشمل : }
$$

توجيـه الانتباه وتركيزه : عندما يقترح اللاعب اهدافا محددة مثنل زيادة نسبة تسجيل

الاهداف في لعبة كرة السلة او تحسين نسبة الارسال الصحيح في الكرة الطائرة او اجادة

ه الضربات الركنيـة في كرة القدم .... الخخ ، فان الاهداف المحددة تجعل اللاعب يركز

$$
\text { انتباهه على تلك المهارات ومن ثم تحسين الاداء. }
$$

ه تعبئة الطاقة والجها : يمكن من خلال وضع الاهداف زيادة الحافز لدى الرياضبين مما

$$
\text { بزيد من تعبئة الطاقة والجهد. }
$$

ه زيادة المثابرة : يؤدي وضع الاهداف الى اطالة مدة التحمل والمثابرة. 


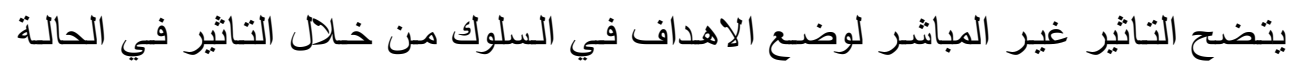

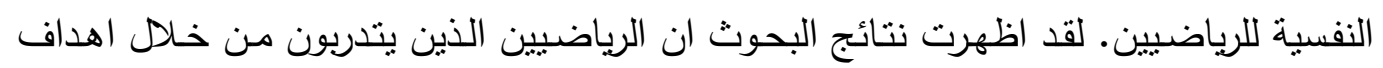

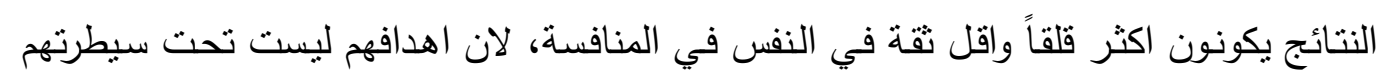

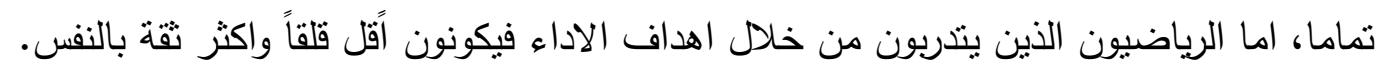
ويحققون نتائج افضل لان اهدافهم لا تعتمد على سلوك المنافس ولكن تعتمد على مقدرتهم.

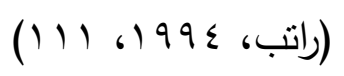

\section{(نماط الاهداف}

ان عملية وضع الاهداف تمثل العملية التي تتم بوساطتها تتمية معايير تقويم الاداء وان

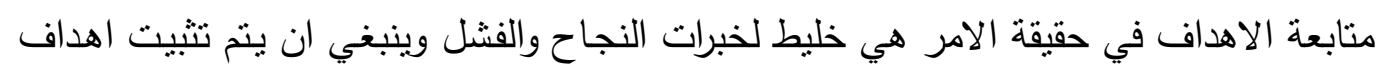
قصيرة المدى واهداف منوسطة المدى واهداف بعيدة المدى.

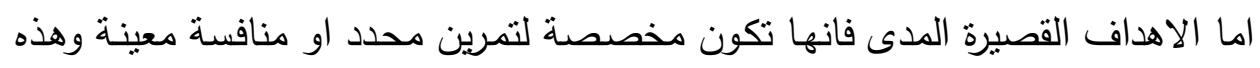
الاهداف بمكن ان تعطي خبرات صغيرة منظمة للنجاح وتسهم في خلق الدافعية عند الرياضيين.

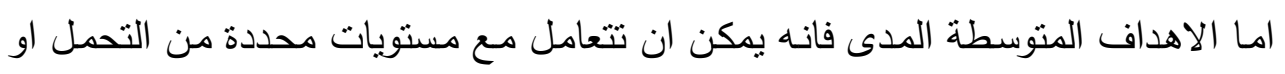
مهارات صعبة يمكن اللاعب الوصول اليها في برنامجه التدريبي.

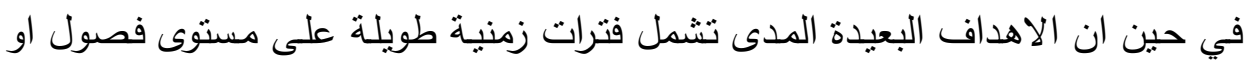

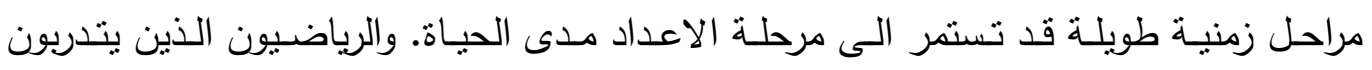

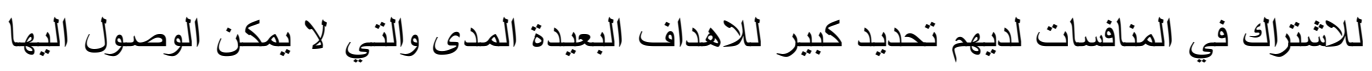

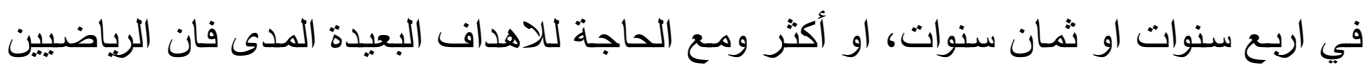

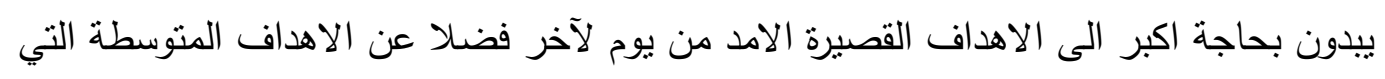
يمكن الوصول اليها في سبيل تحقيق الاهداف الطويلة الامد.

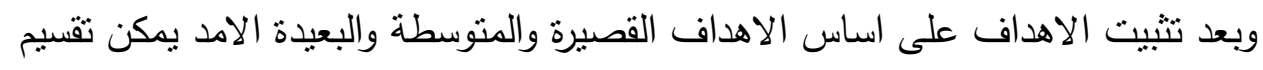

الاهداف الى انواع بالاعتماد على نوع الرياضة او نمطها او الهمية المنافسة.

(Maft,1999,218)

(انت

اهداف النتائج

تركز اهداف النتائج (outcome goals) على نتائج المنافسة لمسابقة معينة مثل كسب

السباق او الحصول على ميدالية او تسجيل نقاط اكثر على المنافس ويلحظ ان تحقيق مثل هذه

الاهداف لا يعتمد على مجهود فردي فحسب وانما على مقدرة المنافس ولعبه ايضاً.

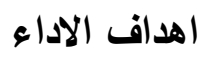


تركز اهداف الاداء (Performance goals) على تحقيق اهداف اداء ومستويات مقارنة بأداء الرياضي السابق لذلك فان اهداف الاداء تعد اكثر مرونة وتحت سبطرة الرياضي. ويلحظ ان هدف الاداء لا يعتمد على سلوك الدنافس إذ إن اهداف الاداء بصفة عامة ترتبط بدرجة أقل من القلق وتفوق أكثر من الاداء اثثاء المنافسة مقارنة باهداف النتائج ان هدف الاداء لا يعتمد على الاهى سلوك المنافس حيث ان اهداف الاداء بصفة عامة ترتبط بدرجة أقل من القلق وتفوق اكثر من الأن

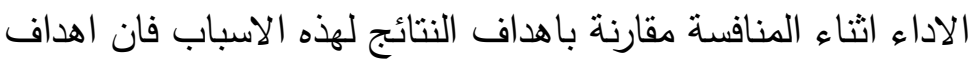

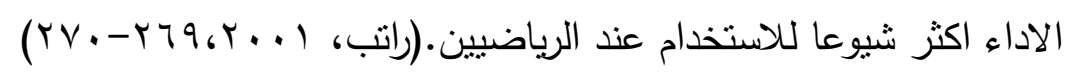

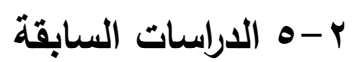

دراسة (دنيس فاريال وويتدي روير) (Denis Fhryal \& Wetdy Rober, 1997)

" اثر اسلوب وضع الهدف في توجيه الرياضيين لتحقيق اهدافهم "

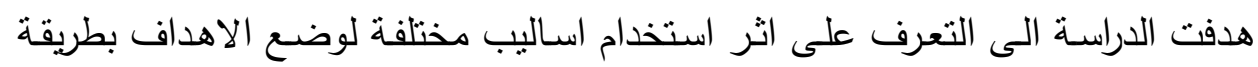

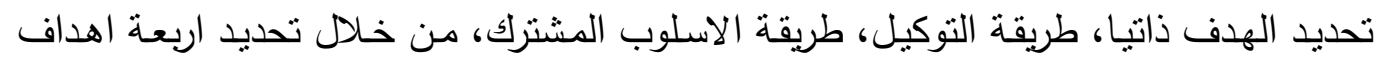

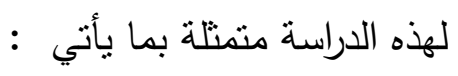
- اهداف التدريب، المعالجة، تحديد الهدف، التقدير

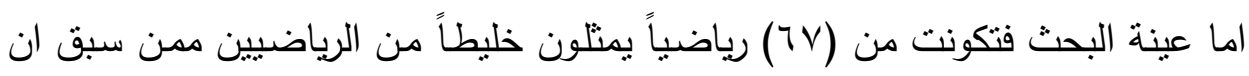
شاركوا في اجراءات وضع الاهداف يمنلون عدائي الساحة والميدان في فعاليات سباق الحواجز

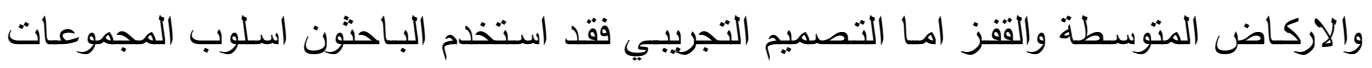
التجريبية ذات الاختبار البعدي اذ قست العينة على ثلاث مجاميع تجريبية كل مجموعة تجريبية تعمل على وفق اسلوب محدد في وضع الاهداف وقد استغرقت هذه الدراسة مدة ثلاثة اثشهر

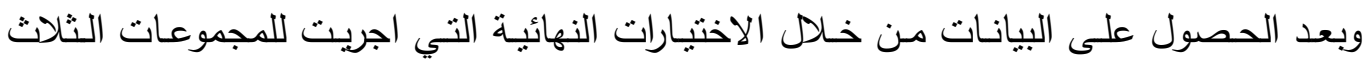
عولجت هذه البيانات احصائيا باستخدام طريقة تحليل التباين. وكانت ابرز النتائج هي :

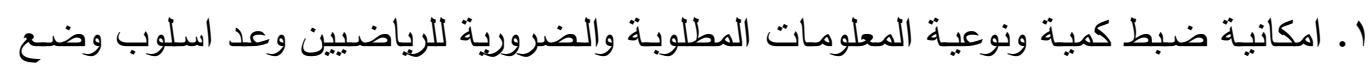
الهدف احد اساليب التعزيز النفسي عند الرياضيين. r. تفوق واضـح لاسـلوب وضـع الهـف بالطريقة النوكيليـة على بقية الاسـاليب الاخرى يليـه الاسلوب المشترك في وضع الهدف ثم اسلوب تحديد الهدف ذاتيا.

(Denis \& Rober, 1997, 15) 
تم استخدام المنهج التجريبي لملائكته وطبيعة البحث.

$$
\text { r r r r r بتمع البحث وعينته }
$$

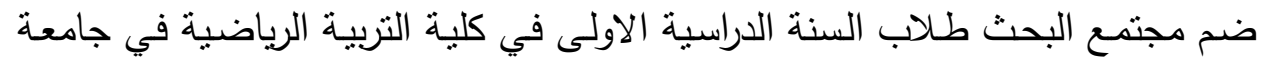

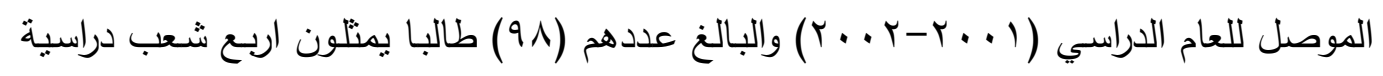

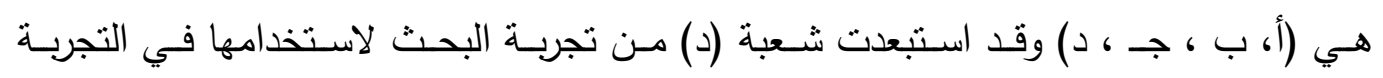

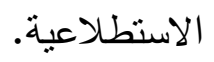

واختيرت عينة البحث بشكل عمدي من الشعب الدراسية (أ، ب ، جـ) لتطبيق تجربـة

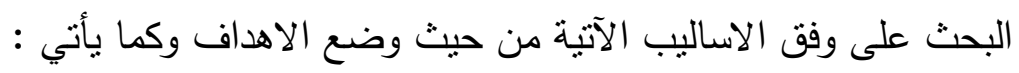

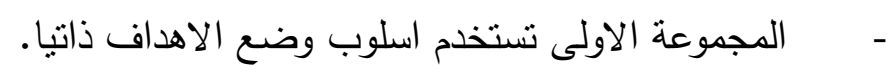

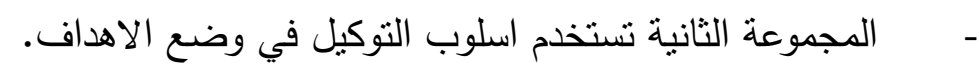

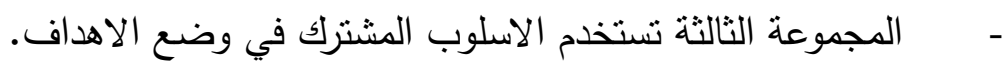

وتم استبعاد عدد من الطلاب وذلك لتحقيق التكافؤ بين المجموعات الثلاث وكما يأتي:.

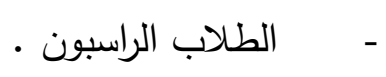

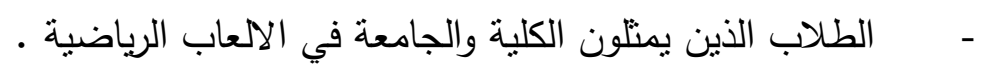

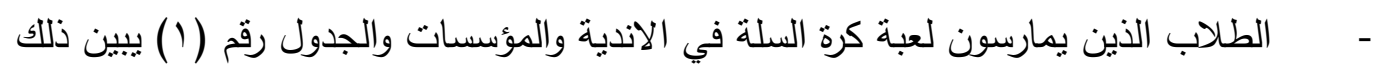

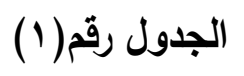

\begin{tabular}{|c|c|c|c|c|c|}
\hline الطلاب & عدد الطلاب & الطلاب & الأسلوب المستخدم & المجموعات & الشب \\
\hline$r$. & $\varepsilon$ & $r \varepsilon$ & أسلوب تحديد الهدف ذاتيا & التجريبية الأولى & -1 \\
\hline$r$. & 0 & ro & أسلوب التوكيل في وضع الأهداف & التجريبية الثانية & $-r$ \\
\hline$r$. & 0 & ro & الأسلوب المشترك في وضع الأهداف & التجريبية الثالثة & r \\
\hline 7. & $1 \varepsilon$ & $V \varepsilon$ & & & المجموع \\
\hline
\end{tabular}

عدد افراد عينة البحث والمجاميع التجريبية

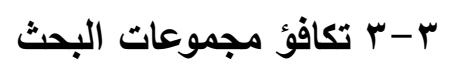


من اجل تحقيق التكافؤ بين مجموعات البحث لبيان تاثير المتغير المستقل (اسلوب وضع الهدف) في دقة التصويب في كرة السلة استخدم الباحثون تحليل التباين باتجاه واحد بين المجموعات للتعرف على دلالة الفروق بين متغيرات العمر ، الوزن، والطول والجدول رقم (r) بيين تفاصيل ذلك

$$
\text { الجدول رقم(r) ( الجمات }
$$

تحليل التباين بين مجموعات البحث في متغيرات (العمر ، الوزن، الطول)

\begin{tabular}{|c|c|c|c|c|c|c|c|}
\hline قيمة (ف) & المتوسطات & الحرية & المربعات & مصدر التباين & وحدة & المتغيرات & ت \\
\hline \multirow[b]{2}{*}{ r.9YI } & $r 1.00 \mathrm{~V}$ & r & $\{r .110$ & بين المجموعات & \multirow[b]{2}{*}{ شهر } & \multirow[b]{2}{*}{ 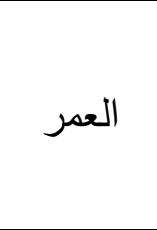 } & \multirow[b]{2}{*}{1} \\
\hline & V.r人o & ov & $\varepsilon r \cdot . T \lambda r$ & المجموعات داخل & & & \\
\hline \multirow[t]{2}{*}{1.911} & $\begin{array}{c}111 . \wedge r \\
0\end{array}$ & r & TrV.TV & بين المجموعات & \multirow[t]{2}{*}{ كغم } & \multirow[t]{2}{*}{ 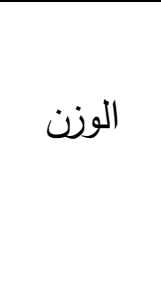 } & \multirow[t]{2}{*}{ r } \\
\hline & $09 . V 7 \varepsilon$ & ov & $\Gamma \varepsilon .7 .7$ & المجموعات & & & \\
\hline \multirow[t]{2}{*}{$1 . r \vee \wedge$} & $\begin{array}{c}\text { VI.TTr } \\
0\end{array}$ & $r$ & 10T.MTO & بين الدجموعات & \multirow[t]{2}{*}{ سم سم } & \multirow[t]{2}{*}{ الطول } & \multirow[t]{2}{*}{$r$} \\
\hline & $00.7 Y_{0}$ & ov & TIV..ro & المجموعات & & & \\
\hline
\end{tabular}

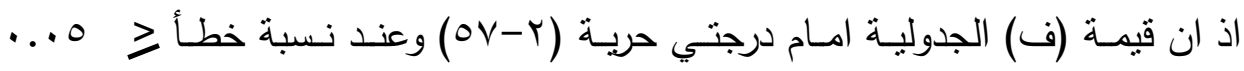

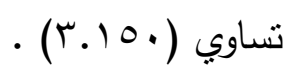

يتبين من الجدول رقم (r) ان قيم (ف) المسوبة لمتغيرات العمر و الوزن و الطول

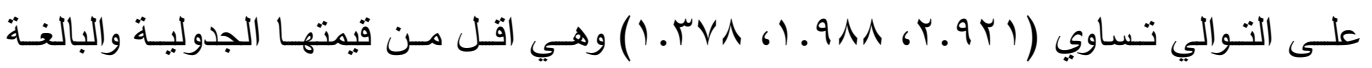

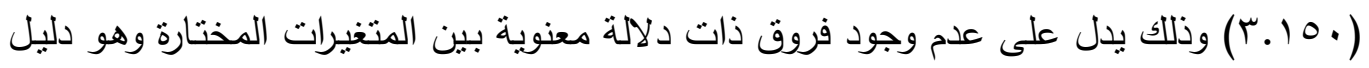
على تكافؤ المجاميع في هذه المتغيرات. r-r-1 التكافؤ في عناصر اللياقة البذنية

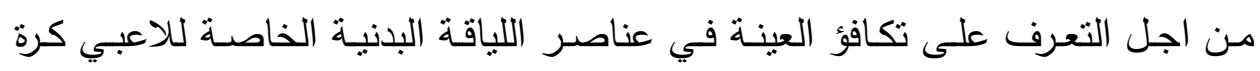

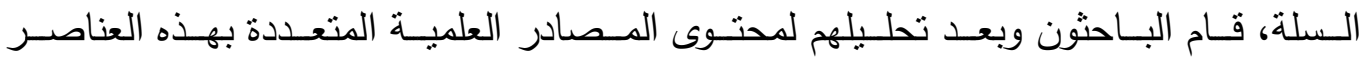

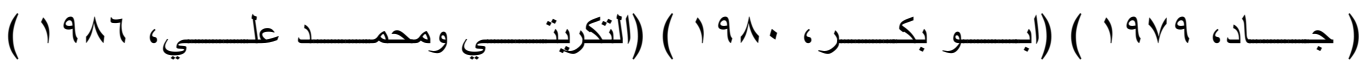




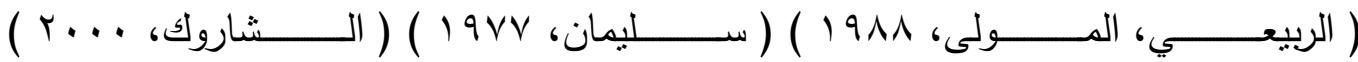

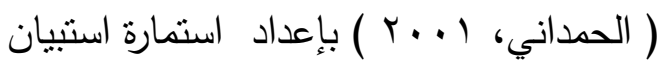

عرضت على عدد مـن ذوي الخبرة والاختصاص" في التربيـة الرياضية وبعد تفريخ الاجابات تم اعتماد العناصر التي حصلت على نسبة اتفاق (0 V \%) فأكثر بحسب ما حدده (بلوم) ( بنيامين وآخرون، 919 ) ) ، وكان عدد هذه العناصر اربعة وبعد ذلك قام الباحثون وبعد تحليله لمحتوى المصادر العلمية الخاصة بالاختبارات ( حسانين، 1990 ) ( ابراهيم، 1999 ) ( علاوي ورضوان، . . . . ) بأعداد استمارة استبيان ضمت الاختبارات الخاصة بعناصر اللياقة البدنية المختارة وعرضت على السادة ذوي الخبرة والاختصاص انفسهم.الجدول رقم( r ) يبين

\section{(الجدول رقم) (r) (ب)}

يبين عناصر اللياقة البدنية الخاصة والاختبارات الملائمة لها وحسب اتفاق السادة الخبراء

\begin{tabular}{|c|c|c|c|}
\hline درجة الاتفاق & 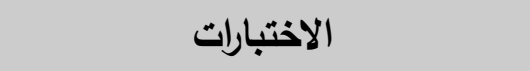 & عناصر اللياقة البدنية & 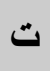 \\
\hline$\% 90$ & اختيار رمي الكرة الطبية زنة r كغم & القوة الانفجارية للذراعين & 1 \\
\hline$\% 9$. & اختبار القزز العمودي من الثبات & القوة الانفجارية للرجلين & r \\
\hline$\% \wedge \wedge . \diamond$ & اختبار عدو •r م & السرعة الانتقالية & r \\
\hline$\% \wedge \neg . \wedge$ & اختيار الجري المتعرج (الزكزاك) & 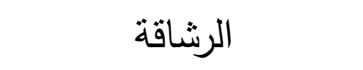 & $\varepsilon$ \\
\hline
\end{tabular}

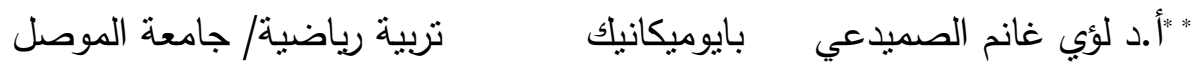

$$
\begin{aligned}
& \text { أ.د وديع ياسين التكريتي علم الحركة تربية رياضية/ جامعة الموصل }
\end{aligned}
$$

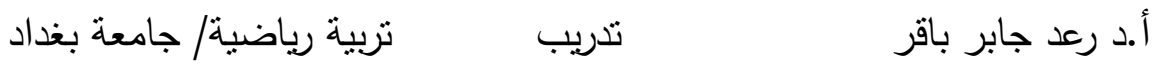

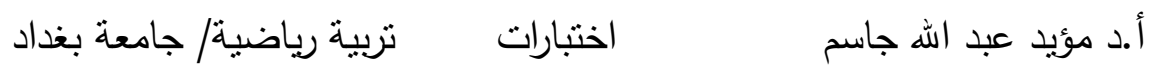

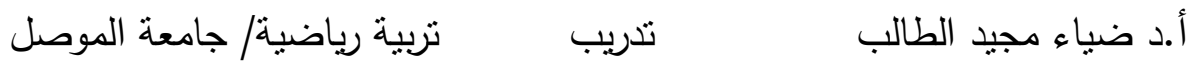

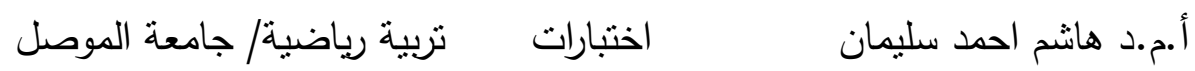


من اجل التحقق من تكافؤ مجموعات البحث في عناصر اللياقة البدنية تم اجراء تحليل

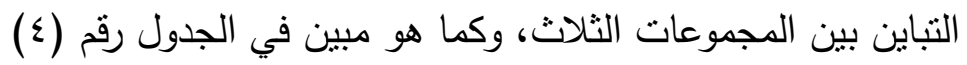

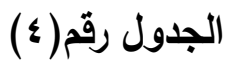

تحليل التباين لمجموعات عينة البحث في عناصر اللياقة البدنية المؤثرة في التصويب

\begin{tabular}{|c|c|c|c|c|c|c|}
\hline قيمة (ف) & متوسط المربعات & الحرية & المربعات & مصدر التباين & المتغيرات & $ت$ \\
\hline \multirow[b]{2}{*}{ T.ITO } & $1 . \wedge \cdot V_{0}$ & r & T.710 & بين المجموعات & \multirow{2}{*}{ اللذرة الانفجارية } & \\
\hline & $. \wedge 0 . \varepsilon$ & ov & $\varepsilon \wedge . \leqslant \vee V$ & داخل المجموعات & & \\
\hline \multirow[b]{2}{*}{$1.0 \%$} & $1 \cdot \leq . \leq \wedge 1$ & r & $r \cdot 1.97 r$ & بين المجموعات & \multirow{2}{*}{ اللرجلين/سم الانفجارية } & \multirow[b]{2}{*}{ r } \\
\hline & $99.4 \leq 1$ & ov & 0707.171 & داخل المجموعات & & \\
\hline \multirow[t]{2}{*}{$1 . V Y \Lambda$} & 1..人ro & r & r.17V & بين المجموعات & \multirow{2}{*}{ الانتقاليةم/ثا } & \multirow[t]{2}{*}{$r$} \\
\hline &. $.7 Y V A$ & or & To.V10 & داخل المجموعات & & \\
\hline \multirow[b]{2}{*}{ I.VTr } & $r .1 .70$ & r & E.rIT & بين المجموعات & \multirow{2}{*}{ الرشاقةم/ثا } & \\
\hline & 1.4101 & ov & $79.5 \cdot \varepsilon$ & داخل المجموعات & & $\varepsilon$ \\
\hline
\end{tabular}

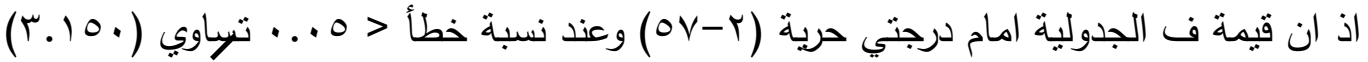

يتبين من الجدول رقم(ع) ان قيم (ف) المحسوبة لعناصر اللياقة البدنية (القوة الانفجارية

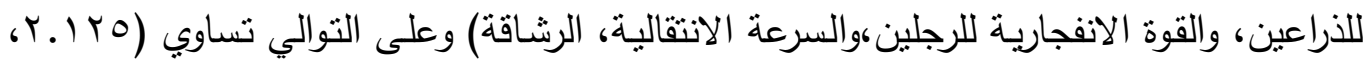

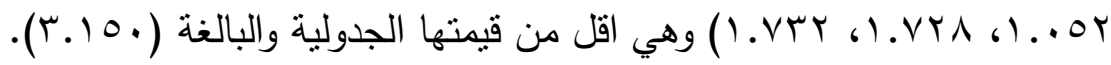

وذللك يدل على عدم وجود فروق ذات دلالة معنوية بين المجموعات الثلاث في عناصر

اللياقة البدنية المؤثرة في التصويب بكرة السلة والذي يؤكد تكافؤ مجموعات البحث في هذه

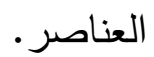

ب- ب التصميم التجريبي

استخدم الباحثون التصميم التجريبي الذي يطلق عليه اسم " تصميم المجموعات المتكافئة

ذات الملاحظة البعدية " .

وحددت المتغيرات في هذه التجرية كما يأتي : 
ب-0 - 1 المتغيرات المستقلة

اسـلوب وضـع الهدف ذاتيـا: بعدهذا المتغير احد اسـاليب وضـع الاهداف المعتمدة في تجربـة البحث ويتم من خلال قيام الطالب بتحديد هدفه ذاتيا لتحقيق عملية تعلمه لمهارات التصويب في كرة السلة بعد قيام التدريسي بشرح هذه المهارات وتطبيقها امام الطالب ومن ثم يطلب منه تحديد الهدف من قبله لاداء المهارة وتطبيقها مستعينا بما يحققه هذا الاسلوب من هن استتارة للافعية عند الطالب تدفعه الى محاولة تحقيق هدفه على افضل وجه.

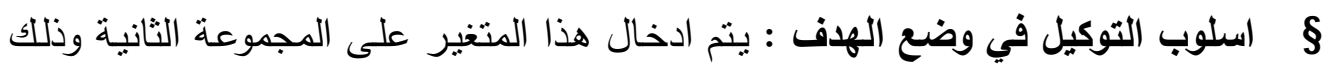
من خلال قيام التدريسي بشرح قائمة الاهداف لتعلم المهارات امام الطلاب جميعهم. ويقوم الطالب بتوكيله في وضـع الاهداف التي سيحاول تحقيقها من دون تدخل لتحقيق الاهداف

المطلوبة.

الاسـلوب المشترك في وضـع الهـدف : في هذا الاسـلوب يناقش التدريسي والطـلاب الاهداف التي يرومون الوصـول اليها ويسجل كلاهما بصورة مزدوجة الاهداف الموضوعة وهذه الحالـة تسمح بتشجيع التفاعل بـين التدريسـي والطـلاب مـن خـلال اجراءات وضـع الاهداف بصورة مشتركة لتطوير مهارات التصويب الثناث.

r r- r r المتغيرات التابعة - تطوير الاداء في التصويبة السلمية في المجاميع الثلاث. ادوات البحث r-V-1 الاختبارات المهارية المستخدمة في البحث.

لاختياراهم انواع التصويب التي يستخدمها الباحثون في اجراءات بحثهم والاختبارات الخاصـة بها اتبع الاسلوب ذاته الذي استخدم في اختيار عناصر اللياقة البدنية واختباراتها ـ اذ وبعد الاطلاع

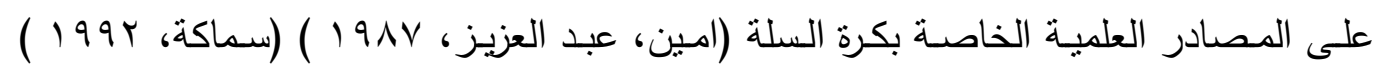

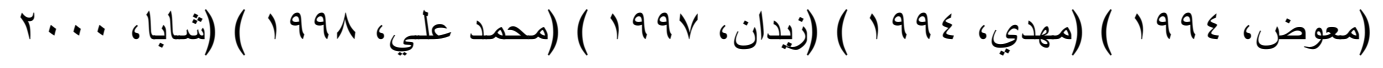
) تم اعداد استمارة استبيان حول انواع التصويب بكرة السلة وعرضت على عدد من ذوي الخبرة والاختصاص في التربية الرياضية والذين تم ذكرهم سابقا وبعد تفريغ الإجابات ووفقاً لنسبة اتفاق السادة الخبراء فقد تم اختيار مهارة ( التصويب السلمي ) لتطبيق البحث بعد ان حصلت على اعلى نسبة اتفاق مقارنـة بمهارتي ( التصويب من القفزو تصويب الرميـة الحرة ) والجدول رقم(0) يبين تفاصيل ذلك. 
(0) الجدول رقماء (0)

يبين نسبة اتفاق السادة الخبراء على مهارات التصويب والاختبارات التي تقيسها

\begin{tabular}{|c|c|c|c|c|}
\hline ن الاتفاق & الاختبارات & الإتقان & مهارات التصويب & ت \\
\hline$\% 94$ & بالتصويب السلمي & $\% 90$ & التصويب السلمي/ثا & 1 \\
\hline$\% 9$. & اختبار التصويب الأمامي & $\% 91$ & التصويب من القفز / عدد & 1 \\
\hline$\% \wedge$ \%.7 & بالتصويب السلمي & $\% \wedge 0$ & تصويب الرمية الحرة & 1 \\
\hline
\end{tabular}

ب-1 - ب التجرية الاستطلاعية

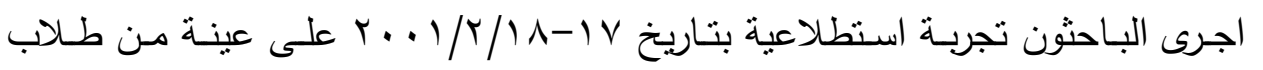

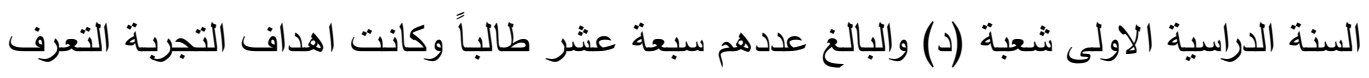

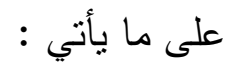

- معرفة الصعوبات وتحديدها والتي يمكن ان تصاحب تطبيق التجربة ومن ثم وضـع الحلول

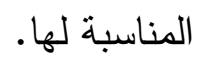

- محاولة التعرف على درجة الفهم والاستيعاب لدى الطلاب في كيفية وضع الاهداف، وتذليل الصعوبات التي تعترضهم ولاسيما في اثثاء التطبيق الفعلي للتجربة.

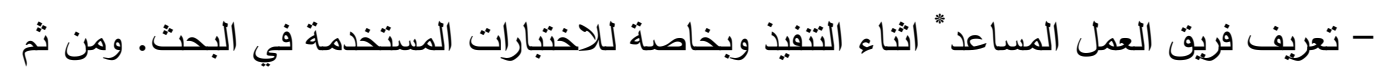
تحديد واجبات كل فرد بدقة.

-التاكد من صلاحية الاجهزة والادوات المستخدمة في البحث.

\author{
"فريق العمل المساعد \\ أ.م.د. ليث محمد داؤد البنا

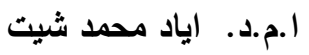 \\ أ. أ.م.د. رياض احمد اسماعيل
}


استغرق تتفيذ التجربـة (r ا ) اسبوعاً وبواقع وحدتين في الاسبوع فبلغ مجموع التجربـة

(Y) وحدة دراسبة هدفت الى تطوير مستوى الاداء باستخدام ثلاثتةانواع مختلفة من اسـاليب

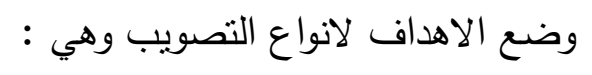

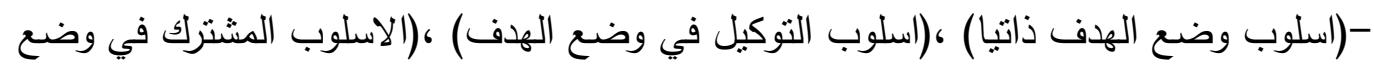

r- وقد وحدت طريقة عرض وشرح المهارة والتمرين من مدرس المادة امام المجموعات التجريبية

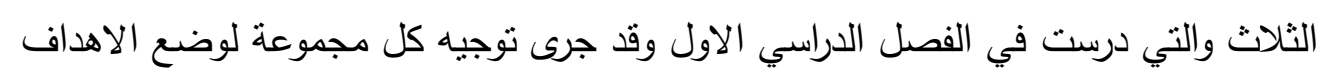

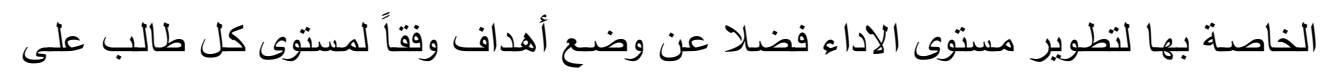

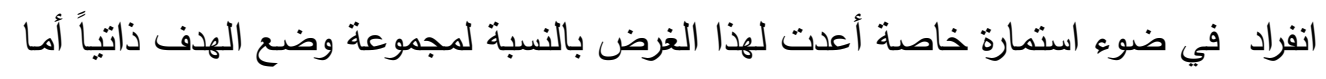

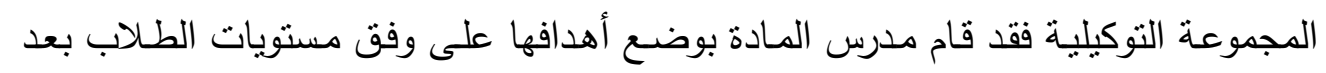

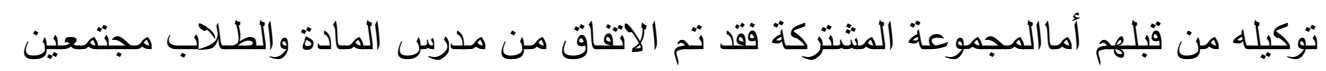

$$
\text { على تحديد ووضع أهداف لنطوير مستوى الأداء. }
$$

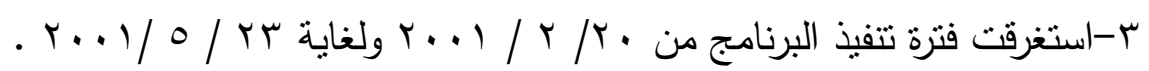

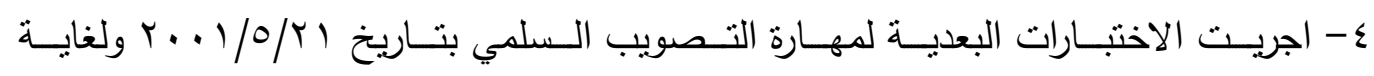

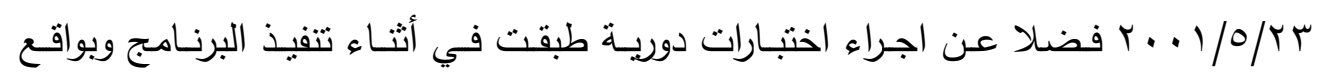

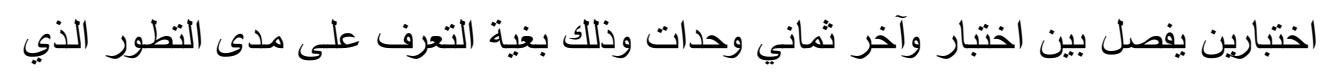

$$
\text { حدث في كل اسلوب من الاساليب المتبعة في البحث. }
$$

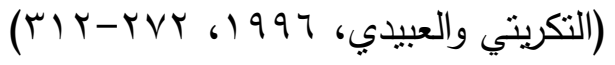
- تحليل التباين باتجاه واحد. - تحله

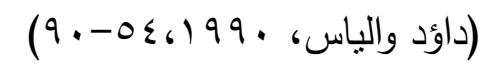
- تحليل التباين متعدد الاتجاه.

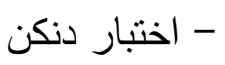




$$
\text { ع - عرض النتائج ومناقشتها }
$$

سينم عرض النتائج ومناقشتها في ضوع ألبيانات الاحصائية التي تم الحصول عليها من عينة

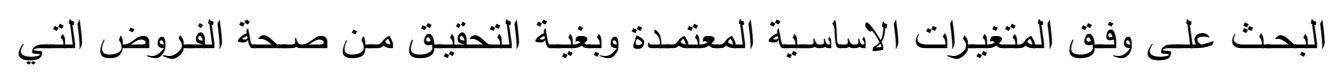
وضعها الباحثّن.

عرض البيانات الخاصة باثر استخدام أساليب مختلفة لوضع الاهداف في تعلم مهارة التصويب السلمي: - n

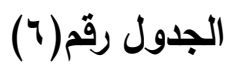

يبين تحليل التباين بين المجاميع والاختبارات المهارية للتصويب السلمي

\begin{tabular}{|c|c|c|c|c|}
\hline قالمسية ف & المربعات & $\tau \cdot د$ & 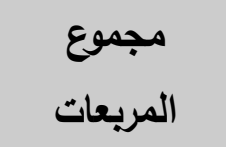 & مصدر التباين \\
\hline **ץ^. . & M.VAr & r & 75.077 & أ.التوكيل في وضيع (أسلوب وضـع الهدف ، الهندف ذاتيـا، \\
\hline$* * \because r . . .1$ & $7 \wedge \wedge .910$ & r & $|r V V . \wedge T|$ & ب.اختبارات مهارة التصويب السلمي \\
\hline \multirow[t]{3}{*}{ T.\&1 } & 8.119 & $\varepsilon$ & $r \wedge . \varepsilon \vee V$ & أ.ب التداخل بين المجاميع والاختبارات \\
\hline & 1.1111 & $|v|$ & $19 \ldots . .0$ & الخطأ \\
\hline & & 189 & 1709.11 .0 & المجموع \\
\hline
\end{tabular}

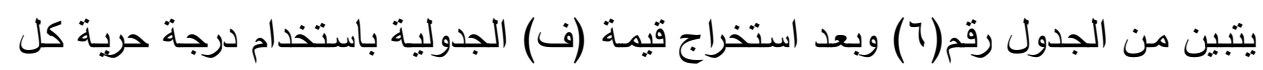

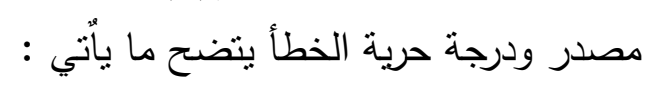

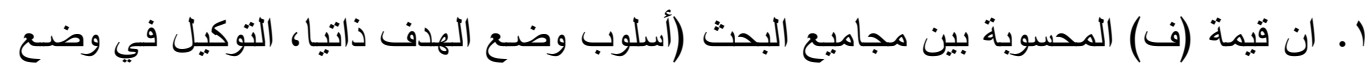

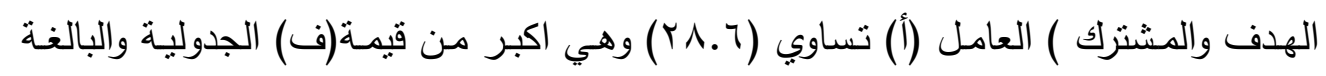

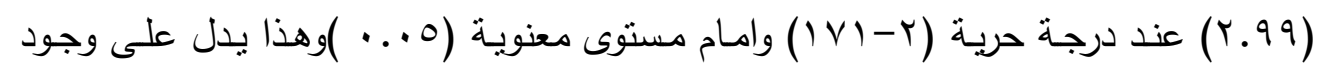

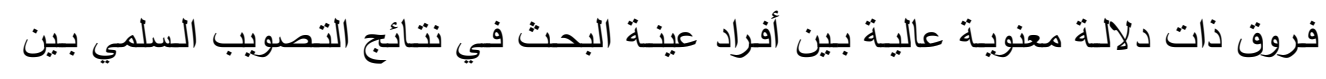

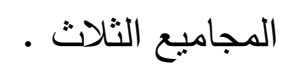

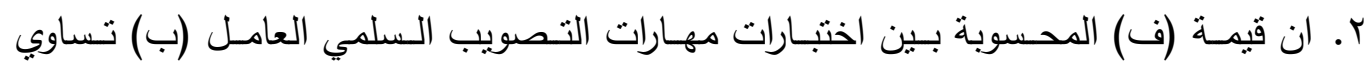

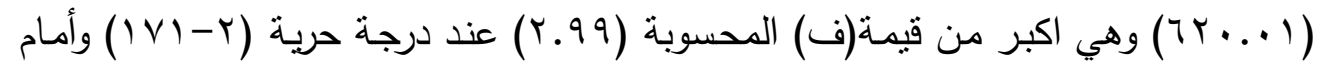


مستوى معنوية (0. . .) وذللك يدل على وجود فروق ذات دلالمة معنوية بين اختبارات مهارة التصويب من القز بين افراد عينة البحث.

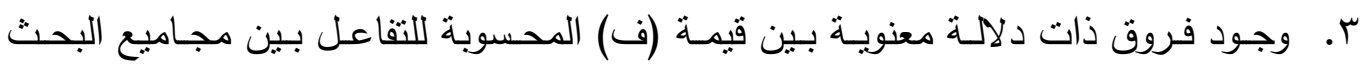

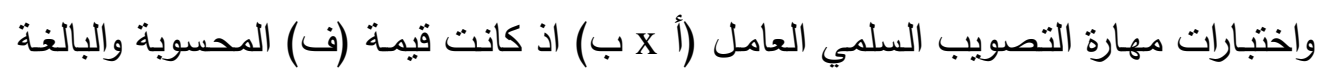

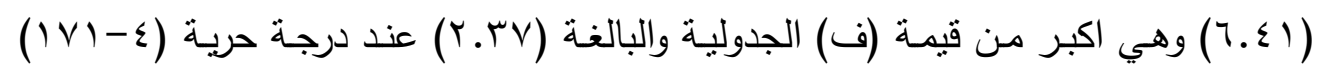

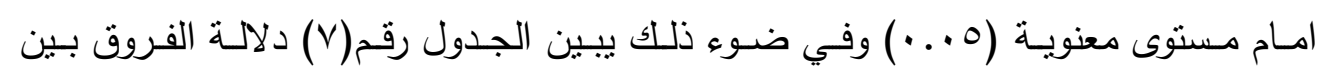
متوسطات نتائج التصويب السلمي بين مجاميع البحث الثلاث وكما يأني :

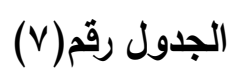

يبين مقارنة الفروق بين مجاميع البحث باستخدام دنكن للتصويب السلمي

\begin{tabular}{|c|c|c|}
\hline متوسط الدرجات & المجاميع & $ت$ \\
\hline & اسلوب وضع الهدف ذاتيا & أ \\
\hline 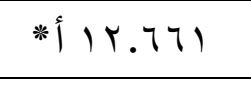 & التوكيل في وضع الهدف & ب ب \\
\hline I Y.r. & الششترك في وضع الهدف & ج \\
\hline
\end{tabular}

" فرق ذو دلالة معنوية

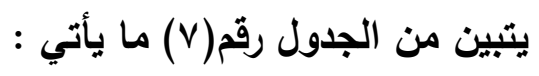

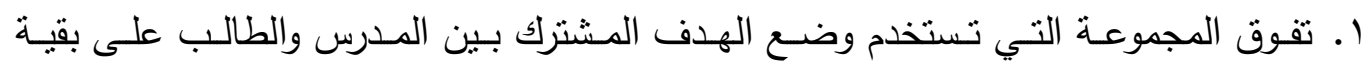

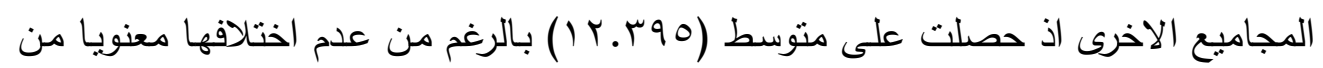

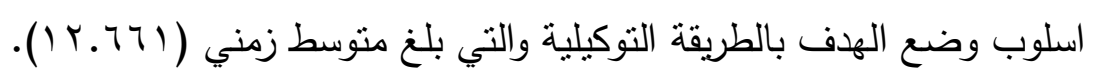

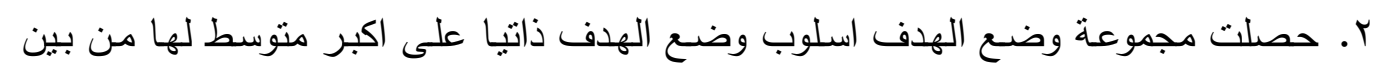

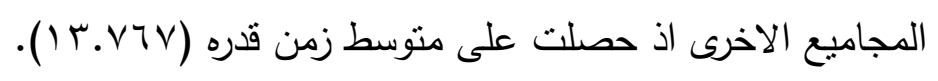

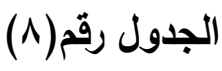

يبين مقارنة الفروق بين متوسطات الاختبارات في التصويب السلمي باستخدام دنكن

\begin{tabular}{|c|c|c|}
\hline متوسط الارجات & الاختبارات & $ت$ \\
\hline ج $17 . .7 \varepsilon$ & الاختبار الأول & 1 \\
\hline . & الاختبار الثاني & r \\
\hline ג & الاختبار الثالث & $r$ \\
\hline
\end{tabular}

| (الفرق ذو دلالة معنوية. 
ينتين من الجدول رقم(^) تفوق الاختبار الثالث لمهارة التصويب السلمي على بقية الاختبارات

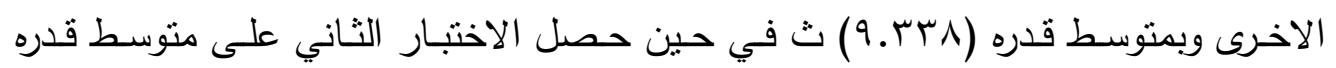

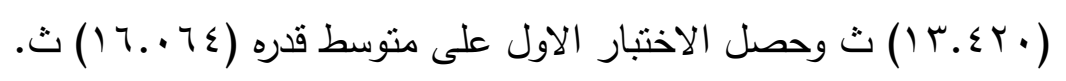

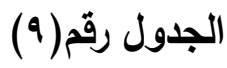

بيين التداخل بين المجاميع والاختبارات المهارية في مهارة التصويب السلمي

\begin{tabular}{|c|c|c|c|c|}
\hline المتوسط & الاختبار الثالث & الاختبار الثاني & الاختبار & \\
\hline IT.VTVT & rr...• اب & $21 \leq .979$ & I + 17.r & ذاتبا \\
\hline 1Y.7T.T & أ. $9.4 \pi$ & Vדז.rו ج & (T.YOT & الهدف \\
\hline IT.r9O & ***. $*$ Y & ع זٓ. الب ج & ـ أهـ 0.7 & الهـف المشترك في وضـع \\
\hline 1 K. $9 \leq .9$ & 9.Tr人т & IT. $\varepsilon r$ & $17 . .7 \leq r$ & متوسط المهارات \\
\hline
\end{tabular}

يتبين من الجدول رقم(9) دلالة الفروق بين مجاميع وضع الاهداف والاختبارات المهارية

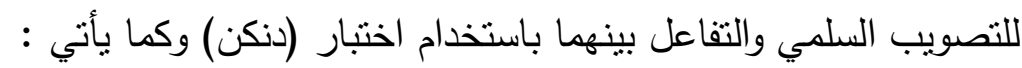

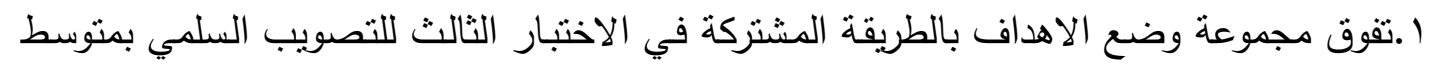

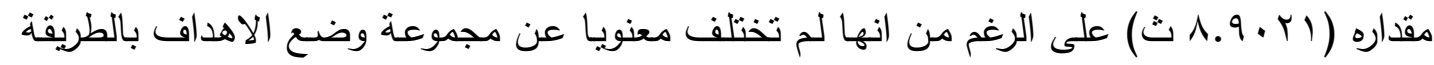

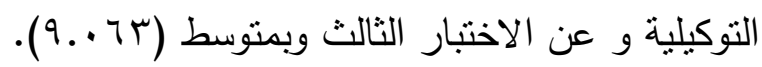

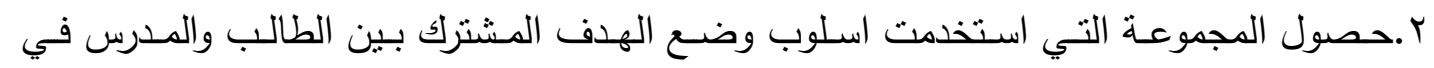
الاختبار الاول للتصويب السلمي (1 ـr.7 () ث وهي لم تختلف معنويا عن مجموعتي تحديد الذات والتوكيلية في الاختبار نفسه.

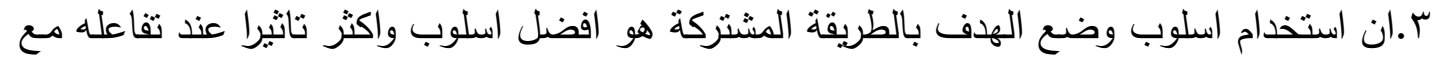

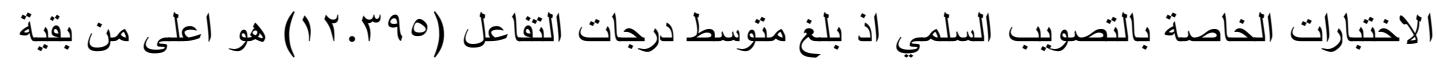
المتوسطات للمجاميع الثلاث في حين ظهر ان الاختبار الثالث هو افضل الاختبارات لمهارة التصويب السلمي و قدره (^r r.9 )) . 


\section{مناقثة نتائج اثر استخدام أساليب مختلفة لوضع الأهداف في تعلم مهارة التصويب السلمي:}

يعزو الباحثون الفروق ذات الدلالة المعنوية في الاساليب المستخدمة لوضع الاهداف والتي

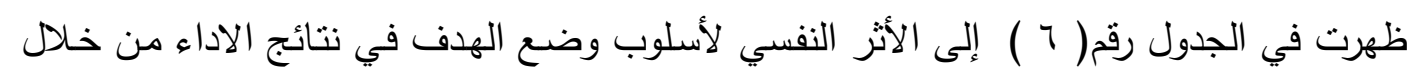

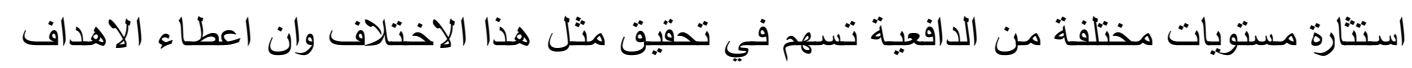

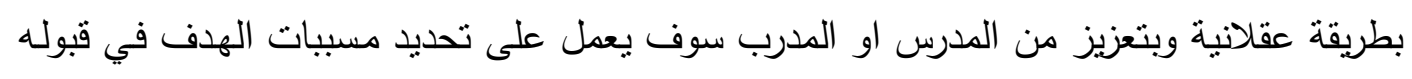

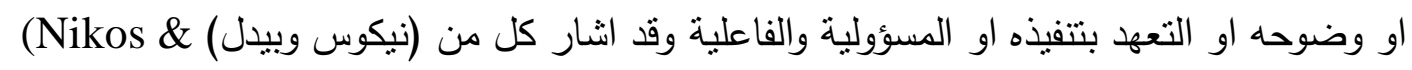

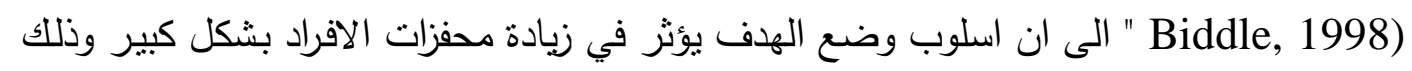

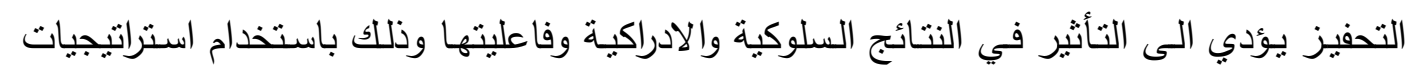

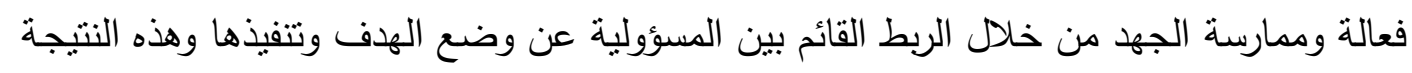

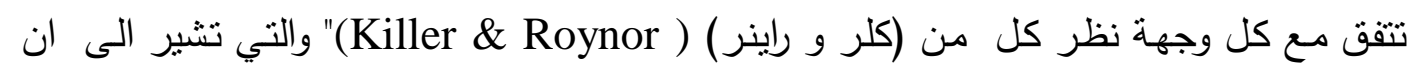
دافعية الإفراد نحو تعلم الخبرات الصفية تزداد اذ ما شعر المتعلمون بان تعلم مثل هذه الخبرات

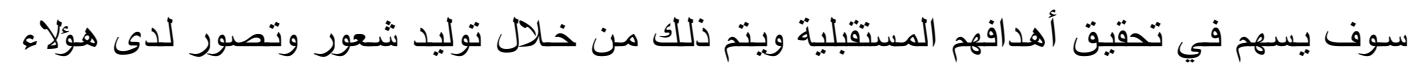

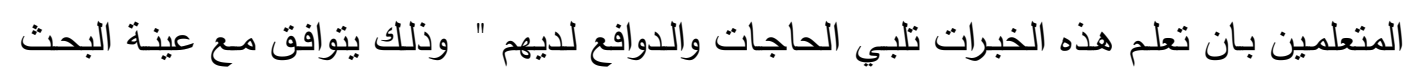

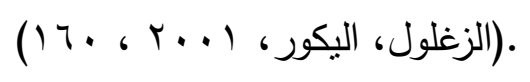

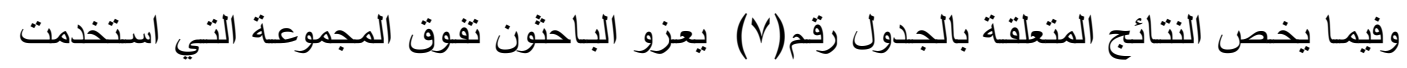

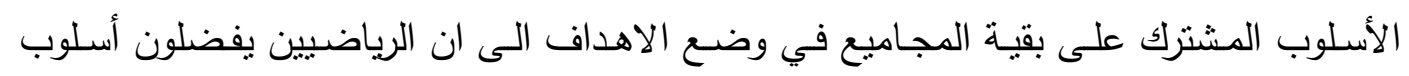

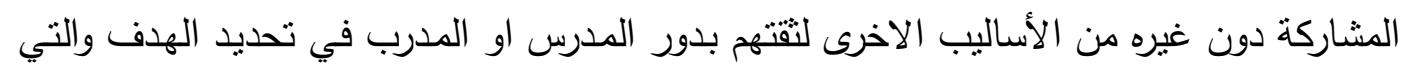

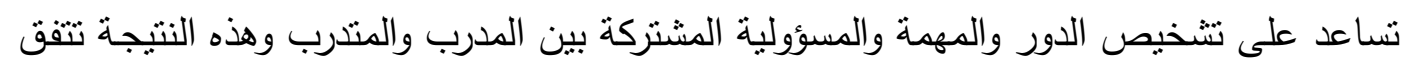

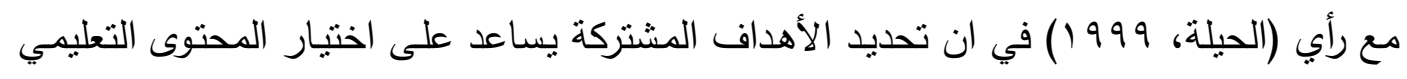

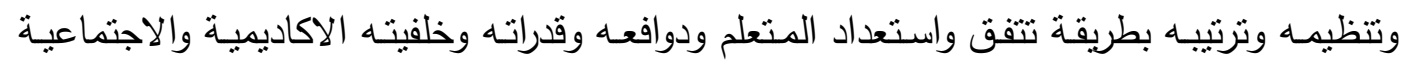

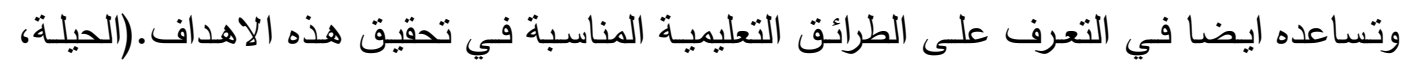
(19996)17

وفيما يتعلق بالنتائج الواردة بالجدول رقم(^) يعزو الباحثون تفوق الطلاب في الاختبار

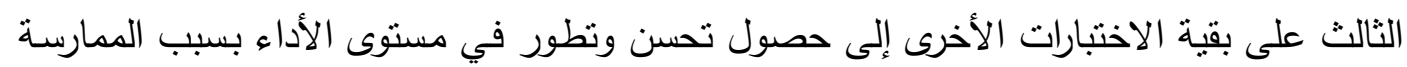
والتدريب ويتفق ذلك مـع مـا طرحهـ (Suinn, 1994) في قدرة المدرب او المدرس لاستئقراء المؤشرات المتعلقة بإثارة الدوافع على شكل طاقة كامنة تعمل على تحسين وتطوير مسنوى اداء

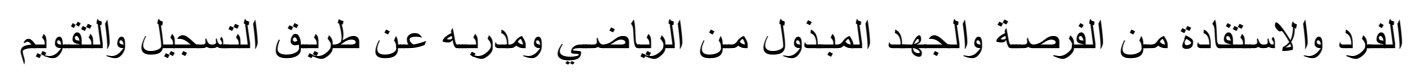

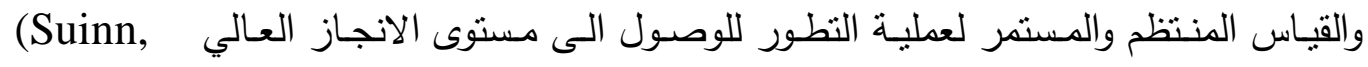




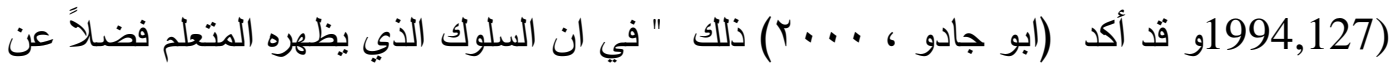

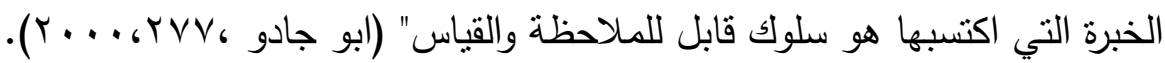
وفيما يتعلق بنتائج التفاعل بين المجاميع والاختبارات المهارية في مهارة التصويب السلمي والمبينة

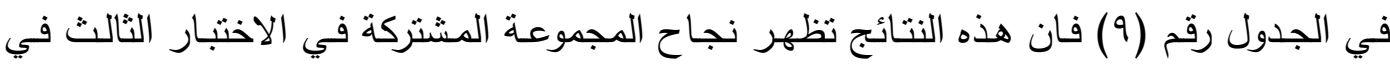
تحقيق نتائج ايجايية مقارنةً بغيرها، اذ ان اثتراك الطلاب في وضع الهدف او تحديده يقود الى الى

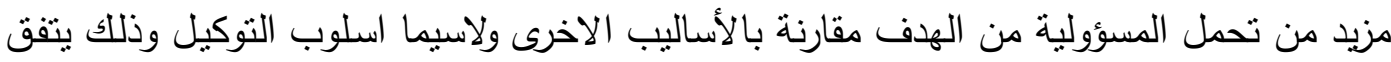

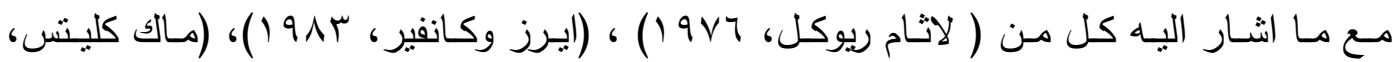

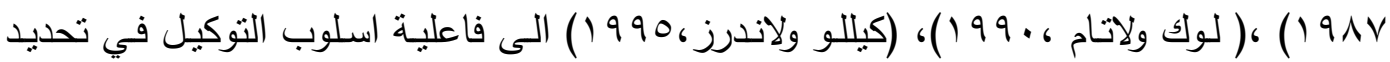
الاهداف في ضوء زيادة الاداء وتحسينه وان مناخ تحديد الهدف هو معيار لقياس فاعلية التطور في مستوى الاداء.Denis \& Rober, 1997,p.p.7) ونلك يرتبط بعوامل تحقيق الهدف مثل هي الالتزام والقبول اللذان يمثلان آليات مهمة للتأثير في دوافع الفرد وما يتحقق من فائدة معرفية مهمة في الحصول على أفكار جيدة يمكن ان يقدمها المدرب او المدرس لكيفية اداء المهمة، وتختلف هذه النتيجة مع ما توصل اليه (جو لا (Gould, (Gould , 1992,120)في ان الرياضيين

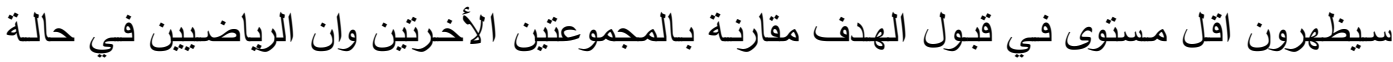
التحديد الذاتي لوضع الهدف سيظهرون أعلى مستوى في تطور الاداء.Gould, 1992,120)

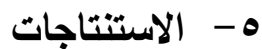

1. يؤثر اسلوب وضع الهدف في تطوير عدد من مهارات التصويب في كرة السلة (التصويب

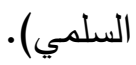

r. فاعلية اسلوب وضع الهدف المشترك في تاثيره في تطوير مهارة التصويب السلمي عند

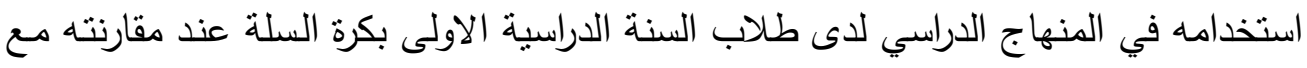

$$
\text { اساليب وضع الهذف الاخرى. }
$$

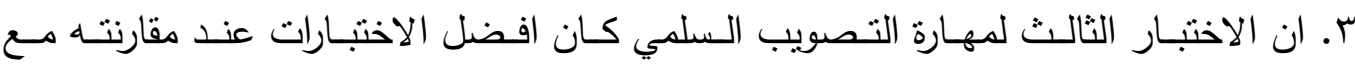
الاختبارات الاخرى في اساليب وضع الهذف المختلفة والذي يشير الى حصول تطور واضح في مستوى الاداء باستخدام اساليب وضع الهدف الثنلاث على الرغم من تفاوتها. ء. ان التفاعل المشترك بين اساليب وضع الاهداف والاختبارات لمهارات التصويب بكرة السلة

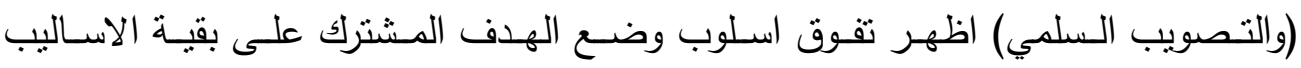
المستخدمة على الرغم من عدم اختلافه معنويا عن اسلوب التوكيل.

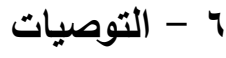

1. استخدام اسلوب وضع الهدف في مناهج التنريس لمادة كرة السلة في كليات واقسام التربية الرياضية لتاثيره الواضح في نطوير مستوى الاداء من خلال زيادة الدافعية عند الطلاب. 
r r تعزيز العملية التعليمية في التربية الرياضية عن طريق تشجيع التفاعل المشترك بين اساليب

$$
\text { وضع الهدف والاختبارات المستخدمة في تقويم الاداء. }
$$

r. التاكيد على اهمية البحث في حقيقة استتارة الدافعية من خلال وضع الاداه الاهداف وتاثيرها في تحسين مستوى الاداء من خلال الاعداد النفسي الجيد للطلاب في مواجهة المواقف المختلفة

$$
\text { عند تعلم المهارات الرياضية. }
$$

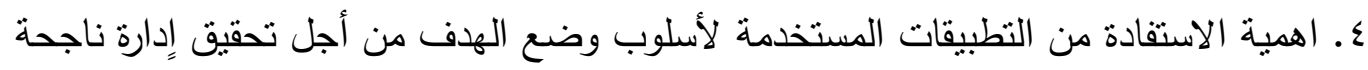

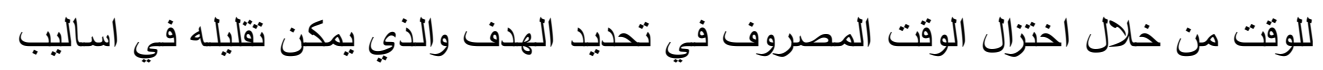
أكثر انتاجية في تحديد العلاقة بين اسلوب وضع الهدف ومستوى التحسن في الاداء.

المصادر العربية

1. ابراهيم ، مروان عبد المجيد (999 1) الاختبارات والقياس في التربية الرياضية

دار الفكر للطباعة والنشر ، عمان .

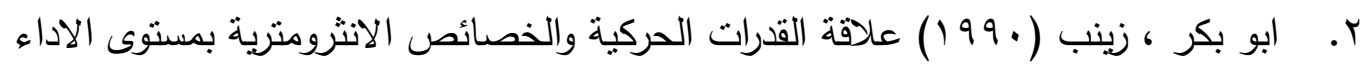

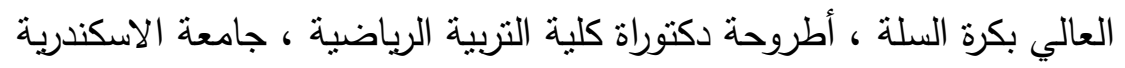

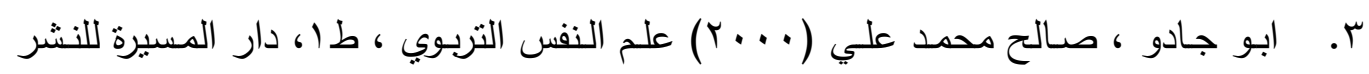

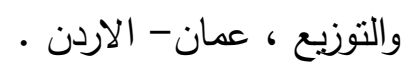

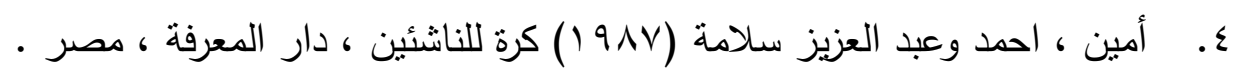

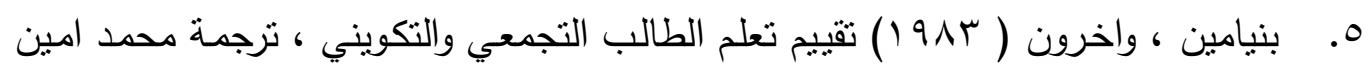
المفتي واخرون ، دار ماكروهل ، القاهرة .

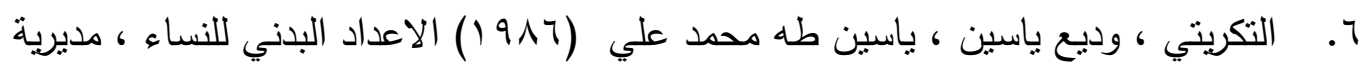

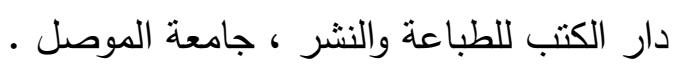

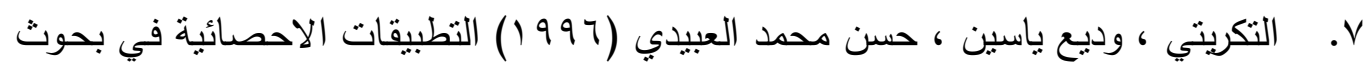

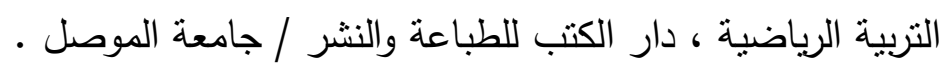

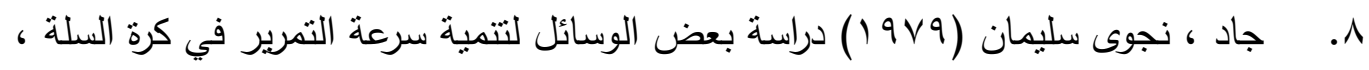
رسالة ماجستير ، كلية التربية الرياضية ، جامعة الاسكندرية .

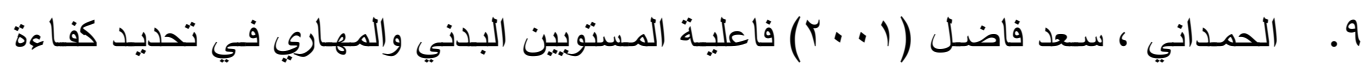
الاداء للاعبي كرة السلة وحسب مركز اللعب ، رسالة دكتوراه غير منشورة ، جامعة الموصل

• 1. الحيلة ، محمد محمود (999 (199) التعميم التعليمي نظرية وممارسة ،طا ، دار المسيرة ،

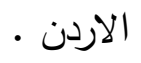


11. ـ ـ (1990) التقويم والقياس في التربية البدنية ،ج اطس، دار الفكر العربي / القاهرة .

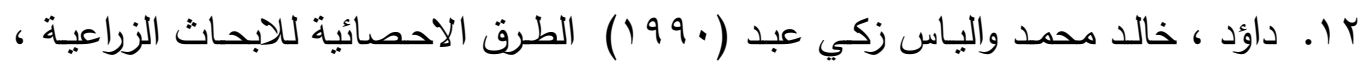

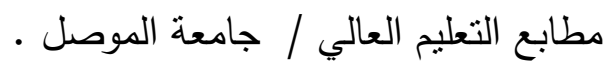

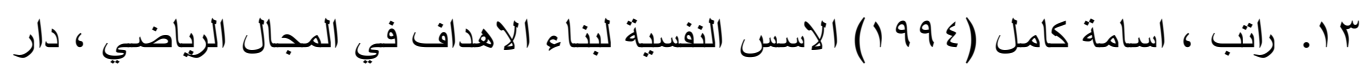

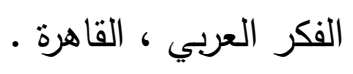

ـ ا. الربيعي ، كاظم عبد ، موفق مجيد المولى ، (911 (1) الاعداد البذني لكرة القد م ، مطبعة

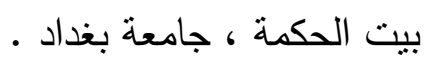

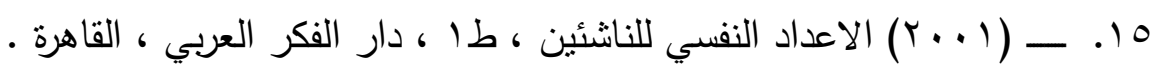

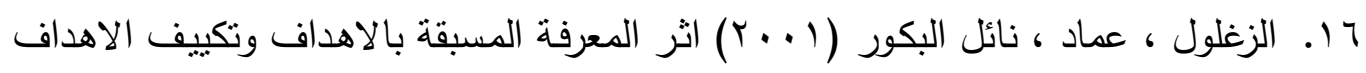

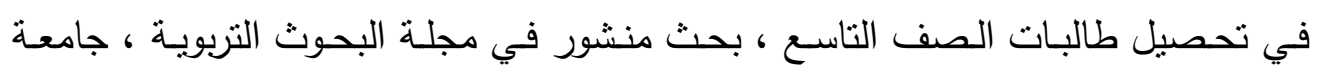

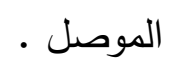

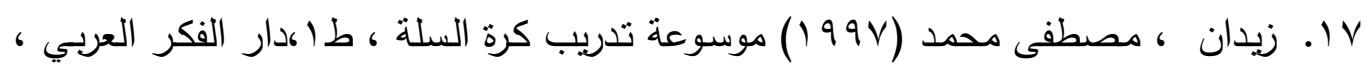
القاهرة .

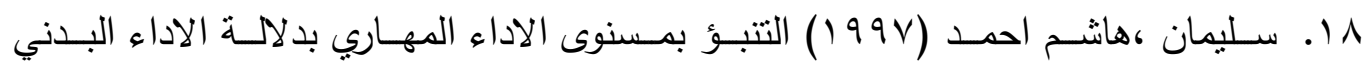

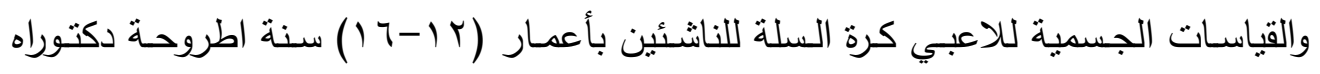
هولية التربية الرياضية ، جامعة بغداد .

9 1. . سماكة ، علي جعفر (1999 1) المرشد التدريبي في كرة السلة الحديثة ، مطابع دار الحكمة ، بغداد.

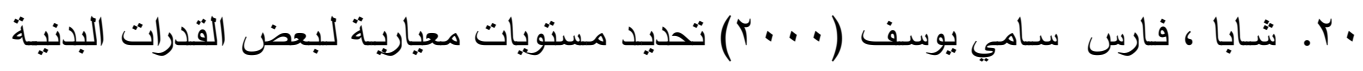

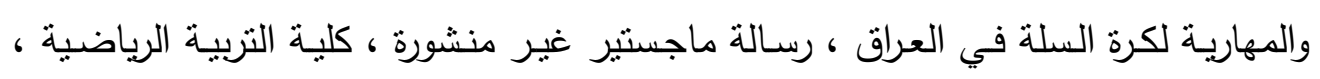
جامعة بغداد .

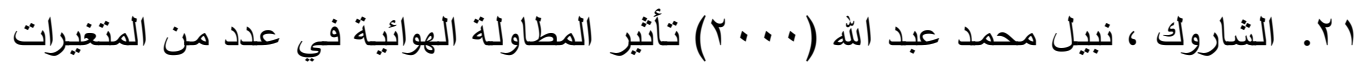

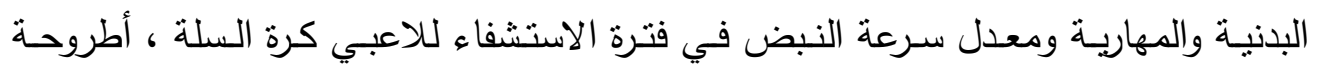

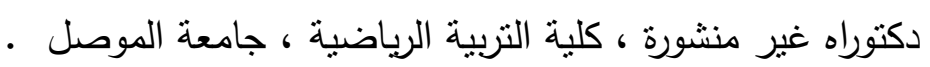

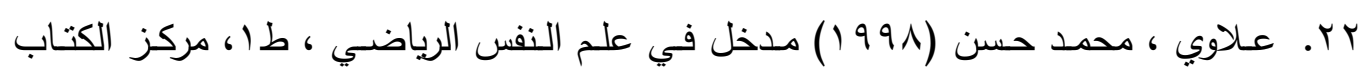
للنشر ، القاهرة .

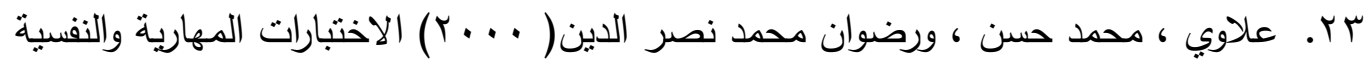
في المجال الرياضي ، دار الفكر العربي ، القاهرة . 


$$
\begin{aligned}
& \text { ؟ ז. محمد علي ، زهير يحيى ، (991 (191) اثر استخدام اسلوب المنافسات الجماعية في تعلم } \\
& \text { عدد من المهارات الهجومية في تتمية القدرات الحركية بكرة السلة ، رسالة ماجسنير ، كلية } \\
& \text { التربية الرياضية ، جامعة الموصل . } \\
& \text { هץ. معوض ، حسن السيد (؟99 1) كرة السلة ، دار الفكر العربي ، القاهرة . } \\
& \text { ج r. مهدي ، احمد كامل ، (99 19 ) ) : كيف تصبح لاعب كرة سلة ، عـالم دار المعرفة ، }
\end{aligned}
$$

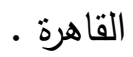

27. Bakket and ofhers, (1990): Sport psychology :Concept and application, john willey \& Sons, New york, U.S.A.

28. Curry , J. pwciss (1989) "Sport Identity and motivation for sport participation, sociology sport Journal vol-G(Vo,3)sociology,

29. Dennis , F.and Rober.W , (1997) The effect of attribution Athletes consulting method cool field expermen intention society of sport psychology , 1x way congress sport psychology .

30. Maft (1999) Sport psychology - Rout lepwe publisher, London .

31. Rushall, B, S . (1996) Some determinants in human competitive performances : Psychological perspective . la k-w kim .

32. Suinn .R. ( 1994) psychology in sport sarjeet publication 